\title{
The Precocious Period: The Impact of Early Menarche on Schooling in India
}

Madhulika Khanna 


\title{
The Precocious Period: The Impact of Early Menarche on Schooling in India
}

\author{
Madhulika Khanna*
}

First Draft: April, 2018

This Draft: July, 2019

\begin{abstract}
Improvements in childhood nutrition increase schooling and economic returns in later life in a virtuous cycle. However, better nutrition also leads to an earlier onset of menstruation (menarche). In socio-cultural contexts where menarche adversely affects educational attainments, early menarche can thus break the virtuous cycle of girls' human development. This paper focuses on one such context, India, and uses the Young Lives Longitudinal Study to show that starting menses before age twelve causes a $13 \%$ decrease in school enrollment rate. Healthier girls have higher learning outcomes at age twelve, but they also start menstruating earlier and are more likely to drop out of school, such that their initial health advantage over other girls in their cohort disappears. Further, dropout rates induced by menarche are higher if girls live in communities with a low average perception of safety among children, while dropout rates are lower in communities with higher expected wages for female-dominated professions.
\end{abstract}

JEL Classification: J16; I24; O12

Keywords: Gender; Social Norms; School Enrollment; Education; India

*Madhulika Khanna: Georgetown University, 3700 O St NW, Washington, DC 20057, mk1469@georgetown.edu. Acknowledgements: I am very grateful to Garance Genicot and Martin Ravallion for their guidance over the course of this project. This paper also benefited from the helpful comments from Ashish Aggarwal, Sarah Baird, Brad Barham, Anja Benshaul-Tolonen, Becka Brolinson, Deepti Goel, Maria Hernandez, Pamela Jakiela, Shareen Joshi, Nishtha Kochhar, Juan Margitic, Umberto Muratori, Deniz Sanin and Andrew Zeitlin as well as seminar participants at Georgetown University and conference participants at the Sustainability and Development Conference, the Midwest Economic Association Conference, the Washington Area Development Economics Symposium, the Midwest International Economic Development Conference and the Georgetown Center for Economic Research conference. I have also benefited from fruitful discussions with several seminar speakers and co-workers at Georgetown University. The usual caveats apply. 


\section{Introduction}

An individual's long-run well-being is influenced by her nutritional status in early years. Improvements in childhood nutrition enhance both the quantity and the quality of schooling. Given the important role of education in economic development, the link between nutrition and schooling becomes a critical tool to improve the quality of life (see Almond \& Currie, 2015 for a review). The predominant framework of conceptualizing the link from childhood to later life outcomes is based on a virtuous cycle of human development that builds in a synergistic relationship between nutrition and learning across ages (Cunha \& Heckman, 2008). For instance, gains in learning today bear higher future economic returns for children with relatively better health.

Early nutrition, however, is also closely linked to pubertal timing among girls, and betternourished girls typically reach menarche (onset of menstruation) before other girls in their cohort (Villamor \& Jansen, 2016). ${ }^{1}$ Therefore, childhood nutrition can influence long-run well-being through two channels among girls: by sparking the virtuous cycle of human development, and by affecting the timing of menarche. The issue arises as to whether early menarche has adverse consequences for girls' schooling in some contexts, severing the symbiotic relationship between childhood nutrition, schooling and economic returns in later life.

The existing evidence on this argument is far from conclusive. Ichino \& Moretti (2009)'s result that menstruation increases female worker absenteeism in Italy has since been refuted in a replication study (Herrmann \& Rockoff, 2012). Futher, Herrmann \& Rockoff (2012) do not find any effect of menstruation on absenteeism among public school teachers in New York City. Oster \& Thornton (2011) triangulate data on the timing of menstrual cycle and school attendance to show that menstruation accounts for only 0.4 missed school days in a 180 day school-year. At the same time, various studies that use qualitative and observational data use girls' self-reports to argue that menstruation is a significant barrier to schooling (for instance, Sivakami et al., 2019; Mason et al., 2013; Sommer, 2010). By showing that pubescent girls' enrollment only responds to construction of sex-separate toilets, Adukia (2017) suggests that privacy and safety concerns during this age are an important determinant of female schooling.

This paper cnontributes to this literature and examines the effect of early menarche on schooling in India: a context where menarche alters the norms of a girl's engagement with her family and her community (Seymour, 1999). In India, menarche is marked by rituals and celebrations (Dharmalingam, 1994), followed by restrictions on the girl's day-to-day activities during her menses (Mahon \& Fernandes, 2010; Kumar \& Srivastava, 2015). Menarche signifies the beginning of a critical period in a girl's life when "she has acquired the capability to reproduce but she has no authority to do so" and her "vulnerability is at its peak" (Dube, 1988). Against this background, the paper seeks to answer whether a social and familial setting that restricts the scope of a young girl's experiences post menarche also breaks the virtuous cycle of human development. Specifically, the paper explores if early menarche affects girls' extensive margin of schooling, her school enrollment.

\footnotetext{
${ }^{1}$ The evidence on the relationship between nutrition and the pubertal timing is less conclusive for boys (Villamer \& Jansen, 2016).
} 
The primary empirical challenge of estimating the impact of early menarche is that girls go through many changes - physical, emotional and cognitive - during adolescence. Any association between early menarche and enrollment may also reflect these confounding changes. The paper uses the data collected by the Young Lives Longitudinal Study, a unique survey that follows a cohort of 1000 children over their childhood, adolescence and early adulthood. A little more than a quarter of the surveyed girls reached menarche before age twelve. The empirical strategy to identify the impact of early menarche of school enrollment uses a difference-in-differences design and exploits the variation in the timing of menarche within the same age cohort. Enrollment status of those girls who had not reached menarche by twelve is the counterfactual for those who experienced an earlier menarche.

Since children within the same cohort are compared, concerns regarding confounding supply side changes in schooling are not relevant. The difference-in-differences design within a cohort is valid if the factors that affect the timing of menarche (such as nutritional environment in early years) do not interact with the enrollment decision. To address this concern, the paper shows that in addition to being associated with better initial nutritional status, early menarche is also associated with a more rapid increase in indicators of physical health. In so far as better nutrition leads to higher educational attainment, these patterns suggest that the effect of early menarche on school enrollment estimated using a difference-in-differences design may be underestimated. Additional concerns regarding the endogenous timing of menarche are addressed by showing that the results are robust to the inclusion of individual fixed effects which de facto account for anything that may be different about the girls who reach menarche before age twelve.

The key result of this paper is that reaching menarche before age twelve causes a $13.4 \%$ decrease in school enrollment rate ( $12.2 \%$ point decrease over the base of age- and gender-appropriate enrollment rate of $90.6 \%$ ). As discussed above, the existing literature explores the association between schooling and menarche through case- and observation-studies (Mason et al., 2013; Sommer, 2010; Sivakami et al., 2019), and by demonstrating the importance of interventions that relate to girls' needs when they are menstruating (Adukia, 2017). This paper complements the existing literature and explicitly establishes a causal link between early menarche and school enrollment.

A corollary of the result that early menarche decreases school enrollment is that the timing of menarche is not a valid instrument for age at marriage if the outcome of interest is also affected by the woman's education. Using the methodology proposed by Conley, Hansen \& Rossi (2012) to undertake inference when the exclusion restriction is suspect, the paper shows that the two-stage least squares estimates that use the timing of menarche to instrument for the timing of marriage are not stable to plausible violations in the exclusion restriction assumption.

In line with the evidence on the physiological relationship between nutrition and menarcheal timing, the paper shows that girls who are taller and have higher BMI reach menarche earlier. There is also suggestive evidence for synergies between nutrition and learning as girls who reach menarche before twelve outperform other girls in their cohort at cognitive tests. However, these girls are also more likely to drop out of school. By fifteen, they lose any education advantage they 
might have had over other girls in their cohort on account of being healthier, potentially because that advantage causes an earlier menarche.

To argue that these result are a consequence of the socio-cultural norms surrounding menarche in India, data collected by the Young Lives study in Vietnam and Peru are used. As is the case in India, girls who reach menarche before twelve are taller and have higher BMI than other girls in their cohort. In neither setting, however, menarche decreases school enrollment.

Results on patterns of time-use show that if enrolled at twelve, time spent at school does not vary by girls' menarche status. In line with Oster \& Thornton (2011), this finding implies that menarche does not affect the intensive margin of education; this could be an artifact of the selected sample of girls who choose to be in school after menarche.

Taken in conjunction with the biological link between better nutrition and early menarche, these findings imply that the behavioral response to menarche, stemming from local socio-cultural norms, can indeed undermine the virtuous cycle of human development for girls. An earlier onset of menarche, therefore, is another channel through which gender gaps in human development emerge and are sustained.

In fact, menarcheal timing transforms young girls' experiences to the extent that $20 \%$ of the girls who reach menarche before age twelve want to grow up to be full-time parents/housewives as compared to only $10.7 \%$ of the girls who have not started menstruating yet. While the construction of gender identity is important as an outcome by itself, it also has consequences for women's labor force participation. Women's sense of self, and not only men's views about their roles are proximate determinants of female labor market outcomes (Bertrand, 2011). Therefore, early menarche has implications that go beyond the outcomes explored in this paper.

Indeed, menarche has effects that persist well into early adulthood. Consistent with the existing literature (for instance, Desai \& Andrist, 2010), the paper shows that girls who reach menarche before twelve are $11 \%$ more likely to be married at nineteen. Moreover, the length of time between the age at which girls drop out of school and the age at which they marry is also lower by 0.89 years for those girls who experience an earlier menarche.

The heterogeneity in the impact of menarche documented in this paper shows that girls are more likely to drop out of school after menarche if they reside in communities with a low average perception of safety among children. They are also more likely to perceive their neighborhoods as unsafe after menarche. By locating an increase in dropout rates at menarche, these results suggest that gender-specific social norms and concerns for safety amplify after this one event. However, in communities with higher expected wages for female-dominated professions, the negative impact of menarche on enrollment rate is mitigated; the difference-in-differences estimate is attenuated in these communities. Taken together, the findings of the paper are consistent with the view of Jayachandran (2015) that it is the interaction between cultural norms and the concurrent economic growth that drives female educational attainment.

The paper is organized as follows. Section 2 describes the socio-cultural norms surrounding menrache in India, and Section 3 presents the underlying conceptual framework. Section 4 describes 
the data followed by a discussion on the empirical strategy in Section 5. Section 6 presents the results describing the impact of early menarche on enrollment, and discusses robustness checks and heterogeneity. Section 7 examines the relationship between age at menarche and other critical outcomes. Lastly, Section 8 discusses the results and concludes.

\section{Context}

Despite being a universal and regularly occuring experience for women, menstruation is surrounded by various myths and taboos. This is especially true of South Asia where these myths and taboos continue to define women's day-to-day activities. The origin of mythical narratives around menstruation can be traced back to Rig Veda which was composed between 1500 and 1200 BC (Chawla, 1994). When Lord Indra slayed a high caste demon, Vritra, part of Indra's guilt was assumed by womankind. His guilt appears every month in the form of their menstrual flow. Therefore, menstruation is considered ritually impure.

The notion of menstruation's ritual impurity is most evident in taboos and cultural practices that confine the scope of women's daily lives. For instance, women are not supposed to enter the kitchen or the prayer room during their menses. Some dietary restrictions, such as prohibition of sour food, are also followed during menstruation (Garg \& Anand, 2001; 2015). In some communities young girls are instructed to stay away from sources of water during their menses for they may pollute it (Mahon \& Fernandes, 2010). A report by Vennam \& Komandhuri (2009) based on qualitative data collected from the cohort studied in this paper further exemplifies the association of menstruation with ritual impurity. Families celebrate their daughters' menarche by hosting a meal for their relatives and friends within the community. Girls are kept at home for five to seven days after menarche. They are not allowed to touch any person during this period.

In South Asia, menarche marks a girl's transition into womanhood. Now that she is a woman, her parents must plan her marriage. Delayed marriage signifies the failure of a girl's parents to discharge their duties (ICRW \& Plan Asia Regional Office, 2013). According to the religious scriptures, by performing the act of kanyadan, or handing over his daughter to her husband, the bride's father earns good virtues. However, if the girl is perceived to be flamboyant or unrestrained it would be difficult to arrange her marriage (Dube, 1988). Parents have to safeguard her virginity until the day of her marriage. Now that she is a woman, she is more vulnerable to sexual harassment, and is observed more carefully by the community members (Singh \& Vennam, 2016). Her mobility and the extent and the scope of her interactions are restricted (Seymour, 1999).

Qualitative observations on the cohort studied in this paper also discuss that now girls are seen as women and as such dress differently post menrache. Girls in Muslim communities may wear a burqa ${ }^{2}$, and in Hindu communities, long skirts and saris instead of their usual frocks. They are no longer allowed to go out alone, even for short distances. Mothers explain that if their daughters do not adhere to these restrictions, the community might disapprove and it will affect their marriage

\footnotetext{
${ }^{2} \mathrm{~A}$ burqa is an outer garment worn by women in public to cover their body and face.
} 
prospects. Importantly, parents are preoccupied with preparing their daughters for marriage and with approval from the local community (Vennam \& Komandhuri, 2009).

Restrictions on mobility as a result of menarche are entwined with the schooling decision. One girl explains that now she wears a burqa while going to school to avoid unwanted attention (Vennam \& Komandhuri, 2009). Girls report being eve-teased, a colloquial term for public sexual harassment, on their way to school. In sum, menarche characterizes tremendous changes in a girl's life that go well beyond the changes in biology.

\section{Conceptual Framework}

Drawing on the discussion on the socio-cultural role of menarche in a girl's life in Section 2, this section describes a simple framework of how the onset of menstruation can affect her education and age at marriage. This framework has two goals: first, it describes a setup under which menarche affects both education and age at marriage. Second, it derives some testable implications for the heterogeneous impact of menarche on schooling.

Formally, parents' choice of length of schooling, and consequently, the age at dropout $(e)$ and age at marriage $(a)$ is modeled as solving the following problem:

$$
\begin{gathered}
\max _{\{e, a\}} b(e)+v(a)+w(e, a)-\alpha \phi(m) c(e) \\
\text { subject to } \\
a \geq m
\end{gathered}
$$

where $b(e)$ is the direct benefit to the parents from their daughter's education which is increasing and concave $\left(b_{e}>0 ; b_{e e}<0\right)$; this could be the psychological benefit from daughter's schooling, and/or the labor market returns to her education. Next, $v(a)$ is the direct benefit to the parents from having their unmarried daughter around the house which is increasing and concave $\left(v_{a}>0 ; v_{a a}<0\right)$; this could be the psychological benefit from having the daughter stay with parents for longer, and/or the value of the labor that daughter performs around the house. ${ }^{3} w(e, a)$ captures the returns in marriage markets, which increase with education $\left(w_{e}>0\right)^{4}$, decrease with age at marriage $\left(w_{a}<0\right)^{5}$ and are concave in each argument $\left(w_{e e}<0\right.$ and $\left.w_{a a}<0\right)$. Further, it is assumed that $w_{e a}>0^{6}$. This assumption implies that the gains due to higher education in marriage market

\footnotetext{
${ }^{3}$ Indeed, in Indonesia parents encouraged their daughters to delay their marriages and work longer for their natal families (Wolf, 1994). In India, improved labor market opportunities for women reduced the likelihood of their marriage (Jensen, 2012). Using a dynamic model of marriage markets with asymmetric information, Wahhaj (2018) shows that improved access to employment can have dynamic effects on marriage markets leading to a delay in the age at marriage.

${ }^{4}$ Behrman et al., (1999) show that the improvements in men's education propels the demand for more educated wives.

${ }^{5}$ Rao (1993) discusses that there is a pressure on women to get married within an acceptable age range, and it becomes increasingly difficult to find a match as they get older.

${ }^{6}$ Adams \& Andrew (2019) use preference elicitation experiments to show that while parents believe that education improves the probability of receiving a good marriage offer for their daughter, it quickly deteriorates with age once she drops out of school.
} 
are larger when the age at marriage is higher. In other words, this formulation of the returns in the marriage market assumes that higher education and early marriage are substitutes. Finally, $c(e)$ represents the cost of education which is increasing $\left(c_{e}>0\right)$ and convex $\left(c_{e e}>0\right)$. Education costs amplify after menarche, and this assumption regarding the cost of education is captured by a multiplicative terms: $\phi(m)$, which is decreasing in age at menarche $\left(\phi_{m}<0\right)$, and $\alpha$, which captures the local safety environment such that higher $\alpha$ implies higher safety and reputation costs associated with attending school. This formulation of the cost function draws from the discussion on safety and reputation costs of schooling after menarche where a later menarche would entail lower aggregate costs of education. Menarche is the effective lower bound on the age at marriage as described by the constraint $a \geq m$.

In this setup, there are three channels through which the timing of menarche affects the choice problem described above: (1) through constraint effects that arise from relaxation of the constraint that the incidence of menarche is necessary for the marriage decision $(a \geq m)$, (2) through direct effects that result from increased the safety and the reputation costs faced by girls after menarche as they travel to and from school, that is, through $\alpha \phi(m)$, and (3) through indirect effects that result from anticipated changes in marriage markets, that is, through the assumed substitution between $e$ and $a$ in $w(e, a)$. Focusing on the interior solution with $a \geq m$, the first-order conditions $\operatorname{are}^{7}:$

$$
\begin{aligned}
b_{e}+w_{e}-\alpha \phi(m) c_{e} & =0 \\
v_{a}+w_{a} & =0
\end{aligned}
$$

Thus, the following comparative statics for education and age at marriage with respect to age at menarche are obtained:

$$
\begin{gathered}
\frac{\partial e(m ; \alpha)}{\partial m}=\frac{\alpha \phi_{m} c_{e}\left(w_{a a}+v_{a a}\right)}{\left(b_{e e}+w_{e e}-\alpha \phi_{m} c_{e e}\right)\left(v_{a a}+w_{a a}-w_{e a}^{2}\right)}>0 \\
\frac{\partial a(m ; \alpha)}{\partial m}=\frac{-w_{e a} \alpha \phi_{m}(m) c_{e}}{\left(b_{e e}+w_{a a}-\alpha \phi_{m} c_{e e}(e)\right)\left(v_{a a}+w_{a a}-w_{e a}^{2}\right)}>0
\end{gathered}
$$

An earlier menarche is associated with lower schooling and earlier marriage. Define two groups of girls where girls who reach menarche before $m^{*}$ constitute the early menarche group, and girls who reach menarche after $m^{*}$ constitute the late menarche group.

Consider the choice problem for girls in the early menarche group. As noted, the timing of menarche may affect the age at marriage through constraint effects, and also through direct effects. If the latter effects were absent, the timing of menarche can be used to isolate the exogenous variation in the timing of marriage while studying the effect of early marriage on various outcomes including education. However, in settings where safety and reputation costs of attending school increase after menarche, menarche has a direct effect on a girl's education and on other outcomes

\footnotetext{
${ }^{7}$ Second-order conditions associated with the interior solution are: (1) $b_{e e}+w_{e e}-\alpha \phi(m) c_{e e}<0,(2) v_{a a}+w_{a a}<0$, and $(3)\left(b_{e e}+w_{e e}-\alpha \phi(m) c_{e e}\right)\left(v_{a a}+w_{a a}-w_{e a}^{2}\right)>0$. These conditions hold under the assumptions of the framework described above.
} 
that are linked to a girl's education, and the exclusion restriction is invalid.

Prediction 1: Menarche induces a decrease in enrollment rate for girls in the early menarche groups, and girls in the early menarche group enter marriage markets at a younger age.

Now consider the choice problem for girls in the late menarche group, that is, when the age at menarche $\left(m^{\prime}\right)$ is above $m^{*}$. Since $\phi_{m}<0$, in this case $\frac{\partial e\left(m^{\prime} ; \alpha\right)}{\partial m}<\frac{\partial e(m ; \alpha)}{\partial m}, \forall m<m^{*}$. Therefore, direct effects of menarche on equilibrium education are diminished for girls in the late menarche group. Although the constraint on the marriage decision is relaxed after menarche, parents can compensate for the delay in the marriage (due to late menarche) by additional education investments because $w_{e a}>0$, further weakening the positive relationship between age at menarche and schooling. The following prediction is derived for girls in the early menarche group:

Prediction 2: The effect of menarche for girls in the late menarche group is weaker than the effect for girls in the early menarche group.

Figure 1 depicts the relationship between menarche and education for two groups of girls. For girls in the early menarche group, the incidence of menarche affects education through both direct and indirect effects, while for girls in the late menarche group, the incidence of menarche affects education predominantly though indirect effects. The primary empirical exercise undertaken in this paper is to estimate the effect on early menarche on school enrollment. In addition, results on the effect of late menarche are also discussed.

This framework can also be used to yield implications for heterogeneity in the impact of early menarche on school enrollment along some policy relevant dimensions. Consider $\alpha_{1}$ and $\alpha_{2}$ where $\alpha_{1}>\alpha_{2}$; higher $\alpha$ implies that safety and reputation costs are more pertinent. Note that $\frac{\partial e\left(m ; \alpha_{1}\right)}{\partial m}>$ $\frac{\partial e\left(m ; \alpha_{2}\right)}{\partial m}$, that is, a larger negative impact of early menarche on schooling when safety and reputation costs are more pronounced.

Prediction 3: The decrease in enrollment due to early menarche is more pronounced if the safety or reputation constraints are more pertinent.

Next, heterogeneity along the returns to education, that is, $b_{e}$ is explored. Since $b(e)$ is concave, higher returns to education implies a lower $b_{e e}$, and consequently a decrease in $\frac{\partial e}{\partial m}$. Since the relationship between the age at menarche and education weakens with higher $b_{e}$, the prediction for heterogeneity in the impact of early menarche along the returns the education is as follows:

Prediction 4: The decrease in enrollment due to early menarche is abated if the potential returns to education are relatively higher.

This framework has to be qualified in several respects. The choice problem is static, and is conceptualized in a unitary household setup. This framework is not formally tested, but it is included to provide an intuitive and parsimonious setup to interpret the key results of this paper. 


\section{Data}

This paper uses data collected by the Young Lives longitudinal study that follows two cohorts of children in Andhra Pradesh ${ }^{8}$ over the course of their childhood, and focuses on the older cohort that was born in 1994-95. Within each sampling site, households were screened to compile a list of eligible children (aged eight in 2001). From this list of households, a sample of 50 children born between January 1994 and June 1995 was randomly selected.

The Young Lives study is ideal for implementing the identification strategy used in this paper given that it exploits the variation in the timing of menarche. Children in a cohort were tracked over their childhood, adolescence and early adulthood. The Young Lives study also collected detailed socio-economic and demographic data from household, child and community surveys. In particular, primary care-givers were asked about consumption expenditure, economic shocks and their perceptions of children's health status. Children took standardized tests that measure their cognitive ability, and were also interviewed about important aspects of their experiences like schooling, time-use, aspirations, social networks and their perceptions of the social milieu. Children were also asked about their marital outcomes in the later surveys. Community surveys were conducted through focus-group discussions. These surveys collected information on topics such as crime, local wages, and public services. The Young Lives study also collected data on children's physical development through on-site anthropometric measurements. Importantly, the second survey round, during which children were about twelve years old, asked girls if they had started menstruating yet, and, if so, at what age.

The first round of the study was conducted in 2002 when these children were eight years old. The next four rounds of data were collected in 2006, 2009, 2013 and 2016. Attrition was low: 94.4\% of the children were tracked across the first four rounds, and $92.4 \%$ were tracked across the five rounds.

There are about 1000 children in the older cohort. Both genders are nearly equally represented in the sample: $48.8 \%$ of the children are boys, and $51.2 \%$ are girls. About one-fourth of the data are collected from urban areas, and the remaining from rural areas. Backward castes constitute $46.46 \%$ of the sample, while scheduled castes are $21.09 \%$, scheduled tribes, $10.91 \%$, and Muslims, $6.06 \%$ of the sample. The remaining sample represents the upper caste households in the state. About $35 \%$ of the children are first-borns.

Although the primary variable of interest is the enrollment status of the children, their test scores are used for supplementary analysis. Peabody Picture Vocabulary Tests (PPVT) and Mathematics tests were administered in the second and third rounds of the survey. PPVT tests are designed to measure receptive vocabulary. In a PPVT test, an examiner shows a set of four pictures simultaneously and asks the children to select the picture that best represents the word spoken by the examiner. For the analysis purpose, children's raw test scores are normalized relative to the distribution of scores in each survey round.

\footnotetext{
${ }^{8}$ Andhra Pradesh was split into Andhra Pradesh and Telangana in 2014. Section ?? in the Appendix describes the administrative and the socio-cultural context of the state of Andhra Pradesh.
} 


\section{Empirical Specification}

The paper exploits the variation in the timing of menarche to identify the effect of early menarche on enrollment. The information on the timing of menarche is taken from the second survey round, when the typical cohort age was twelve. A little more than a quarter of girls had started menstruating by this time. ${ }^{9}$ Following the typology used in Section 5, these girls are referred to as the "the early menarche group", and the remaining girls are referred to as "the late menarche group". ${ }^{10}$

The difference-in-differences strategy employed in this paper compares two groups of children ${ }^{11}$ across the first and the second survey rounds, that is, when they were eight and twelve, respectively. The key equation for this comparison is:

$$
\begin{aligned}
y_{i c t} & =\beta_{0}+\beta_{1} \text { EarlyMenarche }_{i c}+\beta_{2} \text { Round2 }_{i c t}+\beta_{3} \text { EarlyMenarche }_{i c} \text { Round2 }_{i c t} \\
& +\gamma X_{i c t}+\delta_{c}+\epsilon_{i c t}
\end{aligned}
$$

where $y_{i c t}$ is the enrollment status of child $i$ in sampling site $c$ in survey round $t$. EarlyMenarche $e_{i c}$ is an indicator equal to one if child $i$ reached menarche before twelve, and Round2 $2_{i c t}$ is an indicator equal to one when we consider data from the second survey round. $X_{i c t}$ is a vector of child specific characteristics, and $\delta_{c}$ is a set of sampling site dummies. $\epsilon_{i c t}$ is a conditionally-mean-zero error term. As a sampling site is also the primary sampling unit, standard errors are clustered at the sampling site-level. To estimate the impact of early menarche, girls in the early menarche groups are compared to girls in the late menarche group and to boys; $\beta_{3}$ is the difference-in-differences estimator.

Sampling-site fixed effects capture unobserved characteristics of the local region, including cultural practices and the quality of schooling. Sampling-site fixed effects also control for the administrative capacity of the local bureaucracy because the sampling-sites are the sub-district level administrative units. Finally, including sampling-site fixed effects alleviates the concerns of the effect of climate on age at menarche (Sohn, 2016).

Causal identification based on difference-in-differences strategy requires that the timing of menarche is conditionally independent of those factors that also influence enrollment. If the timing of menarche solely depends on random genetic variation, the identification based on a differencein-differences strategy is valid. Kaprio et al. (1995) show that the correlation between the ages at menarche is 0.75 for monozygotic (identical) twin pairs, but only 0.31 for dizygotic (fraternal) twin pairs. Using a seventy-four years long panel study from the United States, Towne et al. (2005) show that almost half of the variation in the timing of menarche is due to genetic factors. However, the

\footnotetext{
${ }^{9}$ Recall data for age at menarche is missing for a small sub-samble of girls. Further, for some girls the recall age of when the started menstruating is higher than the accurately measured current age. Therefore, girls are categorized into two groups.

${ }^{10}$ Using the second round of the nationally representative India Human Development Survey it can be confirmed that starting menses before twelve indeed denotes early menarche as only $15 \%$ interviewed women reached menarche by this age.

${ }^{11}$ There are three relevant groups of children: girls in the early menarche group, girls in the late menarche group and boys.
} 
pre-eminence of genetic factors in explaining the variation in age at menarche is an established fact only for developed countries. In the context of this paper, skeletal height, weight, physical activity and socio-economic status are correlated with age at menarche in South Asia (Bagga \& Kulkarni, 2000; Chowdhary et al., 1999; Dambhare et al., 2012; Rah et al., 2009). Therefore, household size, mother's literacy status, wealth index, sex of the head of the household, caste, an indicator of whether the first language is the most spoken language in the state (Telugu), number of older siblings, number of younger siblings, number of older brothers, number of older sisters and BMI and height at age eight are included as controls. To parse out any confounding effect of children's latent abilities, their score in Raven's test at eight is also included.

Table 1 summarizes these control variables. There are some important differences across girls in the early and the late menarche groups. First, girls in the early menarche group are taller and have higher BMI than girls in the late menarche group and boys. This difference corroborates the evidence on the relationship between age at menarche and nutritional status. Second, in line with the son-biased fertility stopping rule documented in Jayachandran \& Pande (2017), boys have fewer younger siblings and more older sisters. Girls in the late menarche group also have more older sisters than girls in the later menarche group.

To explore the heterogeneity in the impact of menarche on enrollment, a triple-difference specification is estimated. Let the dimension of heterogeneity be $H_{i c}$. The key equation for this comparison when girls in the early and the late menarche groups are compared across the first and the second survey rounds, therefore, is:

$$
\begin{aligned}
y_{i c t}= & \beta_{0}+\beta_{1} \text { EarlyMenarche }_{i c}+\beta_{2}{\text { Round } 2_{i c t}+\beta_{3} H_{i c}+\beta_{4} \text { EarlyMenarche }_{i c} H_{i c}+} \\
& \beta_{5} \text { Round2 }_{i c t} H_{i c}+\beta_{6} \text { EarlyMenarche }_{i c} \text { Round2 }_{i c t}+\beta_{7} \text { EarlyMenarch }_{i c} \text { Round2 }_{i c t} H_{i c} \\
& +\gamma X_{i c t}+\delta_{c}+\epsilon_{i c t}
\end{aligned}
$$

where all variables are defined as in Equation 5.1, $\beta_{7}$ is the main parameter of interest (the tripledifference estimate), and $\beta_{1}$ through $\beta_{6}$ are the estimates of the double interaction and the linear terms. As before, standard errors are clustered at the sampling site-level.

Data on some important aspects of children's experiences were not collected in the first survey round. For these outcomes (such as safety perceptions, time-use etc.), a contemporaneous regression is estimated. For instance, when time-use of girls in the early and the late menarche groups are compared when they are twelve, the specification is:

$$
y_{i c}=\beta_{0}+\beta_{1} \text { EarlyMenarche } i_{i c}+\gamma X_{i c}+\delta_{c}+\epsilon_{i c}
$$

where $\beta_{1}$ is the intent-to-treat estimator of the impact of menarche if the timing of menarche is as good as random once observables are controlled for. In case this assumption does not hold, $\beta_{1}$ is still a useful description that complements the understanding of menarche's effects on children's experiences. As before, $X_{i c}$ is a vector of child specific characteristics, $\delta_{c}$ is a set of sampling site dummies and $\epsilon_{i c}$ is a conditionally-mean-zero error term. 


\section{Results on Enrollment}

\subsection{Descriptive Evidence}

Figure 2 plots school enrollment by gender. A gap in school enrollment across genders emerges when children are twelve and widens as they grow older. At nineteen, the gender gap in the enrollment rate is $25 \%$. Figure 3 plots these trends again, but children are now classified into three groups: boys, girls in the early menarche group, and girls in the late menarche group.

Figure 3 shows that there is no difference in enrollment rates across the three groups when children are about eight. The enrollment rate is still not different for boys, or for girls in the late menarche group, when they turn twelve. The enrollment rate for girls in the early menarche group, however, falls visibly between eight and twelve; while the enrollment rate for girls in the late menarche group shows a sharp drop between twelve and fifteen.

Since Figure 3 uses the typical cohort age, it is worth exploring if the patterns documented in Figure 3 are replicated with exact age data. Figure 4 describes unconditional enrollment probability as a function of more granular age data. As before, the enrollment rate does not vary across the three groups when children are eight. Soon after, a divergent trend emerges for girls in the early menarche group. The enrollment rate for girls in the late menarche group diverges after children turn twelve. A lack of data between the survey rounds, and the consequent extrapolation are partly responsible for the sharp drop observed at ages eight and twelve, for girls in the early and the late menarche groups, respectively.

\subsection{Key Results}

Results from various specifications of Equation 5.1 are shown in Table 2. Columns (1)-(3) compare girls in the early menarche group to girls in the late menarche group, while columns (4)-(6) compare girls in the early menarche group to boys.

Column (1) considers Equation 5.1 while not including any controls and fixed effects: the estimated impact is $-12.3 \%$ points. This estimate changes little when child specific controls and sampling site fixed effects are included. The most conservative specification yields an estimate of $-12.2 \%$ points, still a substantial drop in enrollment rate (Table 2). This drop represents $13.4 \%$ of the average enrollment rate for the girls in the late menarche group at twelve. The estimates effect of the onset of menstruation when girls in the early menarche group is compared to boys is $-10.7 \%$ points in the specification without any controls and fixed effects. Progressively adding controls and fixed effects does not alter the estimates. Estimated $\beta_{3}$ in the most conservative specification is $-11.1 \%$ points, that is, $12.2 \%$ of the enrollment rate for boys at twelve.

If the gender gap in enrollment at twelve is due to early menarche, enrollment rates for boys and girls in the late menarche group should be similar until the latter group start menstruating. Indeed, in a comparison of the enrollment rates between boys and girls in the late menarche group, the difference-in-differences estimate is small (1.2\% points), and not significantly different from zero Table 3. 
The modal reason for dropping out of school between the first and the second survey rounds for boys is "truancy" followed by "needed for work at home". For girls in the late menarche group, the top reasons for dropping out of school are "needed for work at home" and "truancy". For girls in the early menarche group, the modal reason is "other reasons", that is, not one of the reasons listed among the extensive pre-specified options in the survey. The second most often stated reason is "needed for work at home". Clearly, girls in the early menarche group drop out of school due to reasons that are very different from other children in their cohort.

To summarize, there are two key patterns that demonstrate that menarche induces girls to drop out of school. First, there is a substantial drop in school enrollment rate for girls after they start menstruating. This sharp decrease is not experienced by other children in their cohort. Second, after girls start menstruating, the reasons that they cite for dropping out of school are different from the reasons cited by other children in their cohort.

The magnitude of the estimated effect of menarche is comparable to the effect of education related policy reforms. Adukia (2017) found that latrine construction led to an $8 \%$ increase in enrollment among children enrolled in classes 6-8, and a $12 \%$ increase in enrollment among children enrolled in primary school. Kaur (2016) shows that providing free school lunch to primary school students increased the net primary enrollment rate by 5.5\% points. Azam \& Saing (2016) find that a large scale school construction program in low literacy districts increased the likelihood of ever attending primary school by $5.8 \%$ points.

It is worth confirming if the result that reaching menarche between the age of eight and twelve induces a sizable and significant reduction in enrollment rate is an artifact of the socio-cultural importance associated with menarche in the Indian context. Indeed this result is not borne out in the almost exact replications for other countries covered by the Young Lives study. ${ }^{12}$ In Vietnam girls in early menarche group significantly taller than other girls in their cohort, and also have the lowest dropout rate between ages eight and twelve among their peers.

\subsection{Parallel Trends}

The validity of the difference-in-differences strategy hinges on the assumption of parallel trends: the average change in the control group reflects the counterfactual change in the treatment group if there were no treatment. In this context, the assumption of parallel trends implies that the trends in enrollment rate for any two groups will be indistinguishable if their menstruation status does not change across two consecutive survey rounds. While, the nature of the Young Lives study does not allow a test of pre-treatment parallel trends, the enrollment rates for three groups of children at age eight are statistically indistinguishable (Table 1). The parallel trends assumption holds when enrollment rates for girls in the early and the late menarche groups are compared across the third and the fourth survey rounds (Table 4). Parallel trends are also confirmed in comparisons between

\footnotetext{
${ }^{12}$ The other three Young Lives countries are Ethiopia, Peru and Vietnam. These results were replicated for only Peru and Vietnam because only seventeen girls in the Ethiopia had started menstruating by age twelve. Section A.2 in the Appendix discusses these results in detail.
} 
girls in the early menarche group and boys across (1) the second and the third survey rounds and (2) the third and the fourth survey rounds.

Kahn-Lang \& Lang (2018) discuss the need to carefully consider assumptions inherent in difference-in-differences analysis by (1) addressing the differences in the initial levels, (2) exploring if the parallel trends assumption requires a justification of the chosen functional form, and (3) acknowledging that comparing pre-treatment trends does not establish parallel trends during the treatment period.

Concerns (1) and (3) are addressed here by the discussion on parallel trends earlier in this sub-section. Average enrollment rates for children across groups do not differ when the children are eight, that is, in the pre-treatment stage. The comparisons across the third and the fourth survey rounds demonstrate that post-treatment parallel trends hold. Thus, it can be claimed with some credibility that parallel trends would have been the counterfactual across two periods marked by the changing menstruation status for either girls in the early menarche group or girls in the late menarche group.

If the initial distributions of the outcome (enrollment rate in this case) are different across comparison groups, it is difficult to justify the parallel trends assumption using pretesting with linear trends. This is the motivation for the Kahn-Lang \& Lang's (2018) second concern. They agree that it is hard to make a case for one model over the other in the absence of a theory, and recommend testing parallel trends for different functional form assumptions. In addition to the tests using a linear probability model described in above, tests using logit functional form also indicate that the counterfactual trends in enrollment are parallel across comparison groups (Table 4).

\subsection{Robustness Checks}

\section{Robustness to Alternative Hypotheses Spuriously Linking Menarche to School Enrollment}

As discussed above, age at menarche is associated with local environmental conditions, especially in developing countries. Menarche is correlated with better nutritional status in South Asia. However, better nutritional status is associated with higher educational attainments in the same population (Nandi et al., 2016). Since the girls who reach menarche before twelve are healthier, it is unlikely that they dropped out of school on account of poor nutritional status. Importantly, including children's BMI and height when they were eight years old mitigates the concerns of bias induced by the correlation between better nutritional status and earlier menarche. Moreover, in Vietnam, where girls in the early menarche group are also healthier than girls in the late menarche group, reaching menarche before twelve is associated an increase in enrollment rate (Section A.2, Appendix). Therefore, if anything, the estimate of the impact of menarche on enrollment may be underestimated.

High levels of cortisol due to stress can lead to an earlier menarche (Karapanou \& Papadimitriou, 2010). Unexpected negative economic shocks induce mental stress, thereby potentially affecting the age at menarche. Any association between an earlier menarche and school enrollment may in fact be capturing the effect of external stressors on enrollment. To test for the robustness of the results 
described above to this possible source of bias, health emergencies and deaths in the family are used as proxies for external stressors. ${ }^{13}$ Inclusion of negative health shocks and deaths in the children's families do not affect the results discussed above (Table A.3.1, Appendix). Moreover, the incidence of health emergencies and deaths is not different across the households of girls in the early and the late menarche groups (Table 1).

It is plausible that the enrollment patterns reflect these children's latent ability and performance in school. Low ability and poor performing children drop out of school at an earlier age. This is unlikely to be a driving factor in explaining the drop in enrollment among girls in the early menarche group as their test scores are not lower than the scores for girls in the late menarche group (Table 5).

\section{Individual Fixed Effects}

To assuage any other concerns regarding endogeneity of the timing of menarche, difference-indifferences estimates are computed with individual fixed-effects. Including individual fixed effects is an important robustness check as it de facto includes the fixed effects for the household, the community and anything about the child that does not change over time. The estimates of $\beta_{3}$ are remarkably stable when we consider the comparison across the first two survey rounds (Table A.3.2, Appendix). ${ }^{14}$

\section{Randomization Inference}

Randomization inference is a non-parametric method of hypothesis testing that does not rely on asymptotic properties of the error terms. Randomization inference is relevant for the paper as the sample was drawn from twenty sampling sites where the error terms are likely to be correlated within sampling sites. In the empirical estimates described above, this concern was addressed by clustering the standard errors at the level of a sampling site. However, the robustness of these estimates may still be of concern as the sample has a relatively small number of sampling sites (twenty). To address this issue, randomization inference is used: instead of relying on a theoretical distribution the test statistic is comapred to a distribution derived under different possible allocations of treatments. As the number of draws increase, this procedure performs better. Following Young (2018), 2000 replications are used.

Figure A.3.1 in the Appendix shows the distribution of $\beta_{3}$, the placebo impact of early menarche on school enrollment when girls in the early and the late menarche groups are compared. Reassuringly, the placebo estimates are centered around zero, and only three of the 2000 replications estimates reach the estimates result of $12.2 \%$ points. The distribution of the associated t-statistics should approximately be normal and the t-statistic associated with the difference-in-differences estimate should be in tails of the resulting distribution. Indeed, the t-statistics associated with the difference-in-differences estimate fall within the tails of the distribution (Figure A.3.2, Appendix). These results are consistent with the finding of a p-value equal to 0.001 for estimated $\beta_{3}$. None of

\footnotetext{
${ }^{13}$ Health emergencies and deaths in the family are the most significant drivers of a family's descent into poverty in developing countries (Krishna, 2010).

${ }^{14}$ This is not the preferred specification because some of the analysis in the paper compares outcomes across two groups in a given period. Child fixed effects cannot be used in that setup. Same empirical framework is used to discuss all the results in the paper.
} 
the 2,000 replications reach the estimated effect of $11.1 \%$ points when girls in the early menarche group are compared to boys, confirming that the results described in Section 6.2 are not spurious (Figure A.3.3; Figure A.3.4, Appendix).

\subsection{Impact of Attaining Menarche Between Twelve and Fifteen}

Information about menarche status was not collected in the third survey round of the Young Lives study. To explore if reaching menarche after twelve affects school enrollment, girls in the late menarche group can be compared to boys across the second and the third survey rounds. The underlying assumption for such an analysis is that most of the girls in the late menarche group start menstruating between the second and the third survey rounds. The validity of this assumption is tested with the second round of the India Human Development Survey (IHDS). Almost all of the young girls interviewed by the IHDS had started menstruating by the time they were fifteen. The first round of the IHDS was conducted in 2011-12. The second survey round of the Young Lives study was carried out in 2006. Thus, the pattern of age at menarche across the two surveys reflects trends for a similar age cohort. When the complete sample of women interviewed by the IHDS is considered, $90 \%$ of the interviewed women reached menarche before they turned fifteen. Since age at menarche among Indian women is steadily declining (Pathak et al., 2014), the assumption that most girls in the late menarche group reached menarche by the time they were fifteen is supported in these data.

When girls in the late menarche group are compared with boys, the impact estimator is $-4.7 \%$ points, that is, $5.8 \%$ of the average enrollment rate for boys at fifteen (Table 6 ). When a comparison between girls in the early and the late menarche group is considered, $\beta_{3}$ is not significantly different from zero.

In line with the predictions derived from the conceptual framework outlined in Section 3, the estimated effect of late menarche on school enrollment is muted as compared to the estimated effect of an early menarche. Enrollment rates, unlike indicators of physical well-being, do not converge and girls in the early menarche group have persistently higher dropout rates than other girls in their cohort.

\subsection{Heterogeneity in Impact on Enrollment}

Overall, the results show that the decrease in enrollment caused by menarche drives the gender gap in enrollment that emerges between the ages of eight and twelve. This subsection explores how the strength of the relationship between age at menarche and enrollment varies with safety and reputation costs, and with local labor market conditions ${ }^{15}$. This section focuses on the comparison between the girls in the early and the late menarche groups across the first and the last survey rounds.

Reputation and Safety Costs

\footnotetext{
${ }^{15}$ Results along other dimensions of heterogeneity are described in Section A.4 in the Appendix.
} 
In South Asia, the notion of "family honor" is inextricably linked to the behavior of women in the family. As discussed in Section 2, the fear of being labeled as a girl of bad character who may bring dishonor upon the family intensifies as a girl transitions into womanhood after menarche. Further, it has been argued that these concerns are more pertinent among upper castes than lower castes (Eswaran, Ramaswami \& Wadhwa, 2013). For the state of Andhra Pradesh, the evidence from the second round of the IHDS shows that the female mobility is least restricted among women from the scheduled $\operatorname{castes}^{16}$. Further, women from the scheduled castes are less like to practice purdah, a social practice wherein women are physically segregated from men, and/or veil their faces (Table 7). Indeed, the negative effect of menarche of school enrollment is entirely driven by the girls from non-scheduled caste families suggesting that the cultural norms that restrict female mobility could be an important factor in explaining the result that girls drop out of school at a higher rate after menarche (Table 8; p-value: 0.12).

The discussion in Section 2 suggests that the onset of menstruation might alter a girl's perceived needs and experiences of safety in her community. Indeed, a comparison of girls' response to "whether they feel safe in the community" at twelve shows that girls in the early menarche group were $9 \%$ points less likely to strongly agree that they feel safe in their community. The corresponding average for girls in late menarche group was $80 \%$. An immediate implication of this change is that the effect of menarche on enrollment could be more pronounced in relatively unsafe communities. To encapsulate children's concerns and experiences of the safety of their neighborhood, the community level average of boys' safety perceptions is used. ${ }^{17}$ Indeed the decrease in enrollment is larger in communities with low perceived safety (Table 8). Although not statistically significant at the conventional levels of significance, the triple-difference estimate is substantial at $-12.4 \%$ points (p-value: 0.18 ).

\section{Local Labor Market Conditions}

If the potential gains from education are substantial, the negative impact of menrache of enrollment may be mitigated. Since parents base their expectations of their daughter's earning potential on the female wage profile in their neighborhood (Chamarbagwala, 2008; Jensen, 2012), average salaries for female-dominated professions, teaching and nursing, are used as proxies for local wages for educated women. This information was collected through community level focus-group discussions. Triple-difference estimates are computed for the indicator that the average wages for these professions is less than the median for the whole sample. Results based on both the proxies suggest that the negative impact of menarche on enrollment is mitigated in communities with higher wages for women (Table 9). The triple-difference estimate when teachers' wages are considered is $-8.9 \%$ (p-value: 0.16 ) and when nurses' wages are considered is $-10.7 \%$ (p-value: 0.06 ).

\footnotetext{
${ }^{16}$ Scheduled caste is the official designation for the historically disadvantaged caste group in India.

${ }^{17}$ Only data for boys is used as girls' perceptions of safety is affected by menarche.
} 


\section{$7 \quad$ Other Related Outcomes}

While the evidence on parallel trends and a battery of robustness checks described above confirm that early menarche reduces school enrollment rate, how are the two groups of girls different? How do these differences evolve with age? How does early menarche affect outcomes other than school enrollment? As before, this section focuses on the comparison between the girls in the early and the late menarche group across the first and the second survey rounds.

\subsection{Physical Health}

Figure 5 plots BMI for girls in the early and the late menarche groups. Girls in the early menarche group start off with a higher BMI. Increase in BMI between the first and the second survey rounds is higher for girls in the early menarche group (Table 10). ${ }^{18}$ Children's height exhibits similar patterns (Figure 6): girls in the early menarche group are about five centimeters taller than girls in the late menarche group at eight, and they grow at a faster rate (Table 10).

The initial height advantage that girls in the early menarche group had over other girls in their cohort disappears with age (Figure 6). A pattern of pre-menarche growth spurt, and a significant deceleration after menarche is already documented in the literature (Vilamer \& Jansen, 2016). Figure 6 can be thought to depict this deceleration in growth after menarche. This result, however, raises an important concern: do parents also reduce other (potentially complimentary) investments in their daughters after menarche? To explore this, non-food consumption expenditure and diet composition are considered. Non-food expenditure and dietary inputs do not differ across girls in the early and the late menarche groups at twelve (Table 11). Therefore, these comparisons show that menarche does not affect non-educational parental investments.

Next, menarche is a significant risk factor associated with iron deficiency (Sekhar et al., 2017), which is associated with fatigue and weakness. One way in which menarche can affect schooling is the physical repercussions of menstruation, especially in a poor nutrition environment. However, girls in the early menarche group are taller, and have higher BMI than girls in the late menarche group; they also grow taller at a faster pace than girls in the late menarche group (Table 10). Admittedly, BMI and height may not fully capture the incidence of fatigue and weakness. A good proxy for subjective health assessment is the primary caregivers' perceptions of the child's health relative to the child's peers. In line with the results on objective health indicators, menarche improves the primary caregiver's perception that the child is healthier than her peers by $15.3 \%$ points (Table 10).

\subsection{Test Scores}

Another difference between girls in the early and the late menarche groups is their performance in cognitive ability tests. Girls in the early menarche group outperform girls in the late menarche group when children are twelve, although differences in PPVT test scores are not statistically

\footnotetext{
${ }^{18}$ The average BMI levels across groups are still below the threshold for normal levels.
} 
significant (Table 5). Boys also outperform girls in the late menarche group, while there is no difference in the average test scores for girls in the early menarche group and boys at age twelve. However, when the trends in these test scores across the second and the third survey rounds are considered, girls in the early menarche group lose the advantage they had at age twelve. The difference-in-differences estimator on the performance on cognitive tests (PPVT and Mathematics), when girls in the early menarche group are compared to boys across ages twelve and fifteen, is negative. Moreover, the gender gaps in the test scores for both PPVT and Mathematics tests widen as children grow older (Table 6).

\subsection{Time-Use}

When a girl drops out of school, the most immediate change is through her reallocation of the time she used to spend on education-related activities. The decrease in time spent at school and on studying at home translates into an additional twenty-nine minutes on housework and seventeen minutes on household chores. Changes in time-use patterns of other activities are not statistically significant. If the sub-sample of those girls who are still enrolled in school is considered, time spent at school and on studying does not vary with the girl's menarche status, suggesting that menarche does not affect the intensive margin of schooling (Table 13). This is in line with Oster \& Thornton (2011) that menstruation explains only 0.4 missed days in a 180 day school-year.

By inducing a higher dropout rate among girls, early menarche could also affect the timeuse patterns of her siblings. Since girls in the early menarche group take on more housework responsibilities, their siblings theoritially could spend time on other activities. The Young Lives study collects information on the time-use of all the children between the ages of five and eighteen in the household for a typical day in the last week. An important caveat is that the time-use data for siblings is missing for 491 siblings out of the total 1,847 siblings of the Young Lives children.

For both the younger siblings and the elder siblings, their time use patterns do not differ by the timing of their sisters' menarche (Table 14; Table 15). A lack of change in siblings' time-use patterns also suggests that it is unlikely that girls were pulled out of school to help the family with housework.

\subsection{Aspirations}

Besides changes in time-use, by restricting their mobility, menarche also redefines the scope of a girl's social interactions (Seymour, 1999). Do changes in parents' and society's interactions with girls in the early menarche group affect how they see themselves? Menarche increases a girl's desire to become a full-time parent/housewife by $8.6 \%$ points. Notably, only $10.7 \%$ of the girls in the late menarche group report that they want to become full-time parent/housewife when they grow up in the second survey round (Table 16). While girls in the early and the late menarche groups are equally likely to aspire to receive post-high school education, they are less likely to believe that they would reach their desired level education (Table 16). Whether it is the change in aspirations 
after menarche that induces a girl to drop out or it is her withdrawal from formal education that alters how she sees herself is an open question.

\subsection{Marital Outcomes}

At nineteen, $45 \%$ of the girls in the early menarche group are married, while $31 \%$ of girls in the late menarche group are married. The marriage rate increases for both groups between nineteen and twenty-two. At twenty-two, $65 \%$ of the girls in the early menarche group are married, while $54 \%$ of girls in the late menarche group are married (Figure 7). ${ }^{19}$ Once child specific characteristics and sampling site fixed effects are included, girls in the early menarche group are $11.3 \%$ points (p-value: 0.12 ) more likely to be married at nineteen and $11 \%$ points (p-value: 0.16 ) more likely to be married at twenty-two. ${ }^{20}$ The rates at which girls in the early and the late menarche groups get married between the ages of nineteen and twenty-two are also statistically indistinguishable (Table 17).

Figure 8 shows the distribution of age at marriage for girls in the early and the late menarche groups. The distribution of age at marriage for the girls in the late menarche group is shifted to the right of the distribution for the girls in the early menarche group: girls in the late menarche group marry later, on average and at all quantiles of age at marriage. For the restricted sample of ever married girls, the average age at which girls in the early menarche group get married is 0.8 years lower than the average age at which girls in the late menarche group get married (Table 17).

The Young Lives study also collects information on other characteristics of the girls' marriages. Of the girls married by twenty-two, $42.2 \%$ met their husband on the day of the wedding, and $39.4 \%$ married a man chosen by their parents. These features of their marriage are not different across girls in the early and the late menarche groups. Although not significant, the average value of gifts given by the bride's family at the wedding is lower for girls in the early menarche group by about 41000 rupees (in 2013 prices). There is no difference in the average education of the spouses of the girls in the two groups (Table 18).

\subsubsection{Menarche as an Instrument for Early Marriage}

Typically, girls marry after menarche because menarche marks the biological readiness for childbearing, and therefore marriage (Sheela \& Audinarayana, 2003). Indeed girls in the early menarche group marry younger. The difference in the likelihood of being married at nineteen (14\% points)

\footnotetext{
${ }^{19}$ The Young Lives study started collecting data on marital outcomes only from the fourth survey round, when the typical cohort age was nineteen.

${ }^{20}$ There are three key differences in the empirical strategy adopted in this subsection. First, the focus of the analysis is restricted to a comparison between girls in the early and the late menarche groups. Second, the child specific controls correspond to her natal household instead of the household she currently resides in because marital outcomes would have depended on the characteristics on her natal household because The Young Lives study in India is set in a patrilocal society where the married couple reside with the husband's family. Third, instead of an asset index, land-holding of the natal household when children were fifteen is used to capture their natal household's wealth. Since the turnover rates in land markets are low (Basu, 1986), land-holdings would capture the wealth at the time of wedding.
} 
is in the order of the difference in the enrollment rates (10\% points) at nineteen. In addition, once all girls are past menarche, the trends in their enrollment rate are indistinguishable (Table 4). Menarche increases the demand for marriage because now the girl is out of school, or because of the socio-biological relevance of menarche, or because of a combination of the two. Recent evidence points towards the former explanation: using preference elicitation experiments in India, Adams \& Andrew (2019) show that girls' marriage prospects start deteriorating as soon as they leave school, and early dropout accelerates early marriage. However, parents have a strong preference for delaying their daughters' marriage until eighteen, and value their education until up to high school.

There is an important strand of literature that explores the impact of the timing of marriage on various outcomes of well-being for married women and for their offspring. Often, to ensure consistency of the impact estimators, the variation in the timing of menarche is used to isolate the exogenous variation in age at marriage. This strategy was first proposed in Field \& Ambrus (2008), who use it study the effect of women's age at marriage on their educational attainment. Their sample includes women born between 1951-1970 in Matlab region of Bangladesh. At the time, the legal minimum age at marriage was fifteen, and often not binding. For their sample, over $70 \%$ of the marriages took place within two years of menarche. It can be argued that in such a setting age at menarche would have been the effective lower bound for marriage.

However, the margins of the education and marriage decision that are affected by menarche have changed with time. Age at marriage consistently increased between 1950-54 and 1965-70 in South Asia (Jensen \& Thornton, 2003). It was just over sixteen in 1965-1970. The average age at marriage in 1992-93 was twenty (Das \& Dey, 1998). Age at menarche, however, declined by three months between the cohort who were born around 1955-64 and the cohort that was born around 1985-90 (Pathak et al., 2014). The length of time between the age at menarche and marriage increased over this period.

To formally examine the validity of the timing of menarche as an instrument for age at marriage, consider the following setup: the outcome of interest is years of schooling $(Y)$, the endogenous independent variable is an indicator that the girl did not marry until she was eighteen $(X)$ and the indicator for early menarche (menarche before twelve) is used as an instrument for the endogenous variable $(Z)^{21}$. Consider the probability limit of the two-stage least squares estimator:

$$
\operatorname{plim} \beta^{2 s l s}=\underbrace{\beta}_{\text {populationparameter }}+\underbrace{\frac{\operatorname{Cov}(Z, U)}{\operatorname{Cov}(Z, X)}}_{\text {bias }}
$$

If there is no independent relationship between the incidence of early menarche and educational attainment, the two-stage least squares estimator will be consistent. However, if relationship between early menarche and educational attainment is negative (as discussed in Section 6), the

\footnotetext{
${ }^{21}$ These variables are somewhat different from the ones considered in the Field \& Ambrus (2008) to fully utilize the information available in the Young Lives study. Instead of using age at marriage, an indicator that the girl is unmarried until eighteen is used as the endogenous variable as all girls were not married by the time of the fifth survey round.
} 
two-stage least squares estimator is overestimated because $\operatorname{Cov}(Z, X)<0$. The estimated effect may still be qualitatively useful if the size of the bias is not large.

Coley, Hansen \& Rossi (2012) propose a method to undertake inference and generate bounds around the two-stage least squares estimate when the instrument is only plausibly exogenous, that is, when the exclusion restriction is suspect. This method requires the researcher to have a prior about the extent of the violation of the exclusion restriction. To implement this method, the extent of the violation is taken the Young Lives study, a dataset for which this paper establishes that menarche has an effect on education attainment. This prior is then used to estimate bounds around the IV for the described application using the much larger IHDS dataset which covers the cohort of women born between 1957 and $1991^{22}$.

Using early menarche as an instrument for being unmarried until eighteen, the estimated effect of the latter on completed education is 4.6 years (Table A.5.2, Appendix). Following Coley, Hansen \& Rossi (2012), the exclusion restriction is relaxed and it is assumed that the potential direct effect of early menarche is either drawn from (1) a known support with its upper bound set at zero, or (2) from a known distribution. Section A.5 in the Appendix describes the associated methodology in detail. The more conservative bounds around the two-stage least squares estimate are [-7.6, 4.6] and still contain zero.

The extent of violation of the exclusion restriction estimated from the Young Lives data is more than three times the maximum allowed violation that would ensure that the bounds do not contain zero (Figure A.5.2; Figure A.5.3, Appendix). Therefore, the two-stage least squares estimate is not stable to plausible violations in the exclusion restriction which are still smaller than the estimated violation using the Young Lives study.

To summarize, two results discussed in this paper suggest that the timing of menarche may not satisfy the exclusion restriction when used as an instrument for age at marriage in the Indian setting. First, this paper shows that reaching menarche before age twelve leads to a $13 \%$ decline in school enrollment rate. Second, the two-stage least squares estimates when early menarche is used to instrument for the timing of marriage are not stable when strict exogeneity of the instrument is replaced by plausible exogeneity.

\section{Conclusion}

There is a broad consensus that improving nutrition in childhood in developing countries is a long-term economic investment that catalyzes the virtuous cycle of human and economic development. Among girls, however, improvements in health and nutrition have a close biological association with the timing of their pubertal development: better nutritional environment leads to

\footnotetext{
${ }^{22}$ Since the Young Lives study has a relatively small sample size, and consequently the first stage is weak, it is not appropriate to implement the procedure described in Conley, Hansen \& Rossi (2012). Moreover, IHDS has been used for many applications where age at menarche is used as an instrument for age at marriage to study the effect of the latter on outcomes that may be affected by a woman's education (for instance: Sekhri \& Debraj, 2015; Chari et al., 2017; Dhamija \& Roychowdhury, 2018).
} 
an earlier menarche. In socio-cultural contexts where menarche initiates a series of transitions in young girls' lives, the link between better nutrition in early years and higher economic returns in later life may be severed.

This paper has examined the effect of menarche on one component of the virtuous cycle of human development, schooling, in the Indian context where menarche is associated with substantial changes in a girl's life. Using longitudinal data that that follows children over their childhood, adolescence and early adulthood, the paper finds that reaching menarche before age twelve causes a $13.4 \%$ decrease in enrollment rate.

Healthier and taller girls start menstruating at a younger age. At twelve, girls in the early menarche group perform as well as boys in tests designed to measure their mathematical ability and their vocabulary. However, boys outperform girls in the early menarche group when the children are fifteen. Moreover, by fifteen, girls in the early menarche group lose the learning advantage they had over other girls in their cohort at twelve. By inducing an earlier menarche, better nutritional status at age eight may have led to a higher dropout rate. The paper shows that in settings where menstruation is associated with ritual impurity and job prospects for women are limited, the onset of menstruation can induce a familial and/or a societal response that can minimize the long term gains through the synergistic link between better nutrition and schooling.

Given the sizable impact of menarche on education and marital outcomes, improving the access to menses management technology seems to be the most pertinent policy response. Indeed, menstrual hygiene management is a growing sector of international development. However, the evidence on these interventions is not promising. Despite high adoption rates, providing menstrual cups to school girls in Nepal does not improve school attendance (Oster \& Thornton, 2011). Stopford (2011) finds similar patterns in rural Kenya where commercial sanitary napkins usage does not translate into higher attendance. An evaluation of two supplementary interventions in Ghana - distribution of sanitary pads and puberty-related education - does not find any evidence of additional benefits of sanitary pads (Montgomery et al., 2012). A more recent evaluation of menstrual hygiene management products finds some evidence that providing sanitary napkins improved school attendance, while menstrual cups had no effect despite a high take-up (Benshaul-Tolonen et al., 2019). These evaluations examine the effect of menstrual hygiene management technology among the selected group of girls who are still in school post menarche. If menarche affects the extensive margin of education, as is shown here for the Indian context, an absence of any impact of menstrual hygiene management on attendance cannot be taken to be the evidence that menstruation does not affect schooling.

Clearly, early menarche has implications for a girl's life beyond those implied by the change in her physiology. A better understanding of these changes has to be at the center of any policy response. The first step in that direction is an analysis of the interaction between menarche and the enrollment decision. Results from exploring the heterogeneity in the impacts shows that higher dropout rates are located in communities that are relatively unsafe. Indeed, interventions that address the safety concerns of young girls, such as providing bicycles (Muralidharan \& Prakash, 
2017) and separate-sex toilets (Adukia, 2016), have been successful in encouraging higher female enrollment. Further, the impact of menarche on enrollment is more pronounced among girls from non-scheduled caste households where restrictive gender norms are more pertinent. In conservative communities, while families personally reject restrictive norms, they incorrectly estimate that other people accept it and continue to follow it (Bursztyn, Gonzalez \& Yanagizawa-Drott, 2018). These cultural norms, however, are not immutable. Bursztyn, Gonzalez \& Yanagizawa-Drott (2018) show that correcting false beliefs alter behavior. Gender attitudes can also be changed by persuasion and discussion: a social campaign in the Indian state of Haryana that engaged children in discussions about gender equality led to more progressive gender attitudes (Dhar, Jain \& Jayachandran, 2018). Therefore, appropriate policy responses to higher dropout rates among adolescent girls can start by addressing girls' concerns for safety in particular, and the gender based cultural norms in general.

The factors that counter the effect of early menarche on enrollment are equally important. Girls are less likely to drop out of school after menarche if they live in neighborhoods with higher wages for female-dominated professions. One way to interpret these results is against the background of India's rapid economic development in the past few decades. Although socio-cultural norms restrict girls' mobility and a society's progress towards greater gender parity, economic growth can play a significant role in counteracting these rigid norms. 


\section{References}

Adams, A., \& Andrew, A. (2019) Preferences and Beliefs in the Marriage Market for Young Brides. IFS Working Paper W19/05.

Adukia, A. (2017). Sanitation and education. American Economic Journal: Applied Economics, $9(2)$, 23-59.

Almond, D., \& Currie, J. (2011). Human capital development before age five. In Handbook of Labor Economics (Vol. 4, pp. 1315-1486). Elsevier.

Azam, M., \& Saing, C. H. (2017). Assessing the impact of district primary education program in India. Review of Development Economics, 21(4), 1113-1131.

Bagga, A., \& Kulkarni, S. (2000). Age at menarche and secular trend in Maharashtrian (Indian) girls. Acta Biologica Szegediensis, 44(1-4), 53-57.

Basu, K. (1986). The market for land: An analysis of interim transactions. Journal of Development Economics, 20(1), 163-177.

Basu Roy, S., \& Ghosh Dastidar, S. (2018). Why do men rape? Understanding the determinants of rapes in India. Third World Quarterly, 1-23.

Behrman, J. R., Foster, A. D., Rosenweig, M. R., \& Vashishtha, P. (1999). Women's schooling, home teaching, and economic growth. Journal of Political Economy, 107(4), 682-714.

Benshaul-Tolonen, A., Garazi, Z., Nyothach, E., Oduor, C., Mason, L., Obor, D., Alexander, K. T., Laserson, K. F., \& Phillips-Howard, P. A. (2019). Pupil Absenteeism, Measurement, and Menstruation: Evidence from Western Kenya. CDEP-CGEG WP No. 74. Colombia University.

Bertrand, M. (2011). New perspectives on gender. Handbook of Labor Economics (Vol. 4, pp. 1543-1590).

Bursztyn, L., González, A. L., \& Yanagizawa-Drott, D. (2018). Misperceived social norms: Female labor force participation in Saudi Arabia (No. w24736). National Bureau of Economic Research.

Chari, A. V., Heath, R., Maertens, A., \& Fatima, F. (2017). The causal effect of maternal age at marriage on child well-being: Evidence from India. Journal of Development Economics, $127,42-55$.

Chamarbagwala, R. (2008). Regional returns to education, child labour and schooling in India. The Journal of Development Studies, 44(2), 233-257. 
Chawla, J. (1994). Mythic origins of menstrual taboo in Rig Veda. Economic and Political Weekly, 2817-2827.

Chowdhury, S., Shahabuddin, A. M., Seal, A. J., Talukder, K. K., Hassan, Q., Begum, R. A., Rahman, Q., Tomkins, A., Costello, M., \& Talukder, M. Q. K. (2000). Nutritional status and age at menarche in a rural area of Bangladesh. Annals of Human Biology, $27(3), 249-256$.

Conley, T. G., Hansen, C. B., \& Rossi, P. E. (2012). Plausibly exogenous. Review of Economics and Statistics, 94(1), 260-272.

Cunha, F., \& Heckman, J. J. (2008). Formulating, identifying and estimating the technology of cognitive and noncognitive skill formation. Journal of Human Resources, 43(4), 738782.

Dambhare, D. G., Wagh, S. V., \& Dudhe, J. Y. (2012). Age at menarche and menstrual cycle pattern among school adolescent girls in Central India. Global Journal of Health Science, 4(1), 105.

Das, N. P., \& Dey, D. (1998). Female age at marriage in India: trends and determinants. Demography India, 27(1), 91-115.

Desai, S., \& Andrist, L. (2010). Gender scripts and age at marriage in India. Demography, $47(3), 667-687$.

Dhamija, G., \& Roychowdhury, P. (2018). The impact of womenís age at marriage on own and spousal labor market outcomes in India: causation or selection?. MPRA Paper No. 86686.

Dhar, D., Jain, T., \& Jayachandran, S. (2018). Reshaping Adolescents' Gender Attitudes: Evidence from a School-Based Experiment in India (No. w25331). National Bureau of Economic Research.

Dharmalingam, A. (1994). The Implications of Menarche and Wedding Ceremonies for the Status of Women in a South Indian Village. Indian Anthropologist, Vol. 24, No. 1 , $31-43$.

Dube, L. (1988). On the Construction of Gender: Hindu Girls in Patrilineal India. Economic and Political Weekly, Vol. 23, No. 18 , WS11-WS19.

Eswaran, M., Ramaswami, B., \& Wadhwa, W. (2013). Status, Caste, and the Time Allocation of Women in Rural India. Economic Development and Cultural Change, 61(2), 311-333.

Field, Erica, and Attila Ambrus. 2008. Early marriage, age of menarche, and female schooling attainment in Bangladesh. Journal of Political Economy,116(5): 881-930. 
Garg, S., \& Anand, T. (2015). Menstruation related myths in India: strategies for combating it. Journal of Family Medicine and Primary Care, 4(2), 184.

Garg, S., Sharma , N., \& Sahay, R. (2001). Socio-cultural aspects of menstruation in an urban slum in Delhi, India. Reproductive Health Matters, 16-25.

Herrmann, M. A., \& Rockoff, J. E. (2012). Does menstruation explain gender gaps in work absenteeism?. Journal of Human Resources, 47(2), 493-508.

Ichino, A., \& Moretti, E. (2009). Biological gender differences, absenteeism, and the earnings gap. American Economic Journal: Applied Economics, 1(1), 183-218.

ICRW \& Plan Asia Regional Office (2013). Plan Asia Child Marriage Initiative: Summary of Research in Bangladesh, India and Nepal. Bangkok: Plan Asia Regional Office.

Jayachandran, S. (2015). The roots of gender inequality in developing countries. Annual Review of Economics, 7(1), 63-88.

Jayachandran, S., \& Pande, R. (2017). Why are Indian children so short? The role of birth order and son preference. American Economic Review, 107(9), 2600-2629.

Jensen, R. (2012). Do labor market opportunities affect young women's work and family decisions? Experimental evidence from India. The Quarterly Journal of Economics, 127(2), 753-792.

Jensen, R., \& Thornton, R. (2003). Early female marriage in the developing world. Gender \& Development, 11(2), 9-19.

Kahn-Lang, A., \& Lang, K. (2018). The Promise and Pitfalls of Differences-in-Differences: Reflections on '16 and Pregnant' and Other Applications (No. w24857). National Bureau of Economic Research.

Karapanou, O., \& Papadimitriou, A. (2010). Determinants of Menarche. Reproductive Biology and Endocrinology, 8:115.

Kaprio, J., Rimpelä, A., Winter, T., Viken, R. J., Rimpelä, M., \& Rose, R. J. (1995). Common genetic influences on BMI and age at menarche. Human Biology, 739-753.

Kaur, R. (2016). There are Free Lunches in Life: Impact of Mid Day Meal Program on School Enrollment in India.

Koerselman, K., \& Pekkarinen, T. (2018). Cognitive consequences of the timing of puberty. Labour Economics, 54, 1-13.

Krishna, A. (2010). Who became poor, who escaped poverty, and why? Developing and using a retrospective methodology in five countries. Journal of Policy Analysis and Management, 29(2), 351-372. 
Kumar, A., \& Srivastava, K. (2011). Cultural and social practices regarding menstruation among adolescent girls. Social Work in Public Health, 26(6), 594-604.

Mahon , T., \& Fernandes, M. (2010). Menstrual hygiene in South Asia: a neglected issue for WASH (water, sanitation andhygiene) programmes. Gender and Development, Vol. 18, No. 1, Water, 99-113.

Mason, L., Nyothach, E., Alexander, K., Odhiambo, F.O., Eleveld, A., Vulule, J., Rheingans, R., Laserson, K.F., Mohammed, A. \& Phillips-Howard, P.A. (2013). 'We keep it secret so no one should know'-A qualitative study to explore young schoolgirls attitudes and experiences with menstruation in rural Western Kenya. PloS one, 8(11), p.e79132.

Montgomery, P., Ryus, C. R., Dolan, C. S., Dopson, S., \& Scott, L. M. (2012). Sanitary pad interventions for girls' education in Ghana: a pilot study. PloS one, 7(10), e48274.

Muralidharan, K., \& Prakash, N. (2017). Cycling to school: increasing secondary school enrollment for girls in India. American Economic Journal: Applied Economics, 9(3), $321-50$.

Nandi, A., Ashok, A., Kinra, S., Behrman, J. R., \& Laxminarayan, R. (2015). Early Childhood Nutrition Is Positively Associated with Adolescent Educational Outcomes: Evidence from the Andhra Pradesh Child and Parents Study (APCAPS)-3. The Journal of Nutrition, 146(4), 806-813.

Oster, E., \& Thornton, R. (2011). Menstruation, Sanitary Products, and School Attendance: Evidence from a Randomized Evaluation. American Economic Journal: Applied Economics, Vol. 3, No. 1, 91-100.

Pathak, P. K., Tripathi, N., \& Subramanian, S. V. (2014). Secular trends in menarcheal age in India-evidence from the Indian human development survey. PLoS One, 9(11), e111027.

Persico, N., Postlewaite, A., \& Silverman, D. (2004). The effect of adolescent experience on labor market outcomes: The case of height. Journal of Political Economy, 112(5), 1019-1053.

Rah , J. H., Shamim , A. A., Arju, U. T., Labrique, A. B., Rashid, M., \& Christian, P. (2009). Age of Onset, Nutritional Determinants, and Seasonal Variations in Menarche in Rural Bangladesh. Journal of Health Population and Nutrition, 802-807.

Rao, V. (1993). Dowry 'inflation' in rural India: A statistical investigation. Population Studies, 47(2), 283-293.

Sekhar, D. L., Murray-Kolb, L. E., Kunselman, A. R., Weisman, C. S., \& Paul, I. M. (2017). Association between menarche and iron deficiency in non-anaemic young women. PloS one, $12(5)$, e0177183. 
Sekhri, S., \& Debnath, S. (2014). Intergenerational consequences of early age marriages of girls: Effect on children's human capital. The Journal of Development Studies, 50(12), 1670-1686.

Seymour, S. C. (1999). Women, family, and child care in India: A world in transition. Cambridge University Press.

Sivakami, M., van Eijk, A. M., Thakur, H., Kakade, N., Patil, C., Shinde, S., Surani, N., Bauman, A., Zulaika, G., Kabir, Y., Dobhal, A., Singh, P., Tahiliani, B., Mason, L., Alexander, K. T., Mamita, B. T., Laserson, K. F., and Phillips-Howard, P. A. (2019). Effect of menstruation on girls and their schooling, and facilitators of menstrual hygiene management in schools: surveys in government schools in three states in India, 2015. Journal of Global Health, 9(1).

Sheela, J., \& Audinarayana, N. (2003). Mate selection and female age at marriage: A micro level investigation in Tamil Nadu, India. Journal of Comparative Family Studies, 497-508.

Singh, R., \& Vennam, U. (2016). Factors Shaping Trajectories to Child and Early Marriage: Evidence from Young Lives in India. Young Lives Working Paper 149.

Sohn, K. (2016). The influence of climate on age at menarche: Augmented with the influence of ancestry. HOMO-Journal of Comparative Human Biology, 67(4), 328-336.

Sommer, M. (2010). Where the education system and women's bodies collide: The social and health impact of girls' experiences of menstruation and schooling in Tanzania. Journal of Adolescence $33,521-529$.

Stopford, A. L. (2011). The Effect of Commercial Sanitary Pad Use on School Attendance and Health of Adolescents in Western Kenya (Doctoral dissertation)

Towne, B., Czerwinski, S. A., Demerath, E. W., Blangero, J., Roche, A. F., \& Siervogel, R. M. (2005). Heritability of age at menarche in girls from the Fels Longitudinal Study. American Journal of Physical Anthropology, 128(1), 210-219.

Vennam, U., \& Komandhuri, A. (2009). Young Lives Qualitative Research: Round 1, India, Young Lives Technical Note No. 21.

Villamor, E., \& Jansen, E. C. (2016). Nutritional determinants of the timing of puberty. Annual Review of Public Health, 37, 33-46.

Wolf, D. L. (1992). Factory daughters: Gender, household dynamics, and rural industrialization in Java. University of California Press.

Wahhaj, Z. (2018). An economic model of early marriage. Journal of Economic Behavior \& Organization, 152, 147-176. 
Young, A. (2018). Channeling Fisher: Randomization Tests and the Statistical Insignificance of Seemingly Significant Experimental Results. The Quarterly Journal of Economics, 134(2), 557-598. 


\section{Figures}

\section{Early Menarche Group}

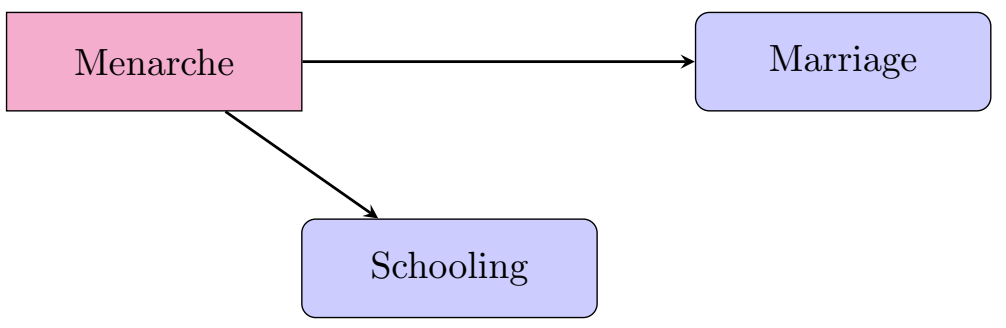

\section{Late Menarche Group}

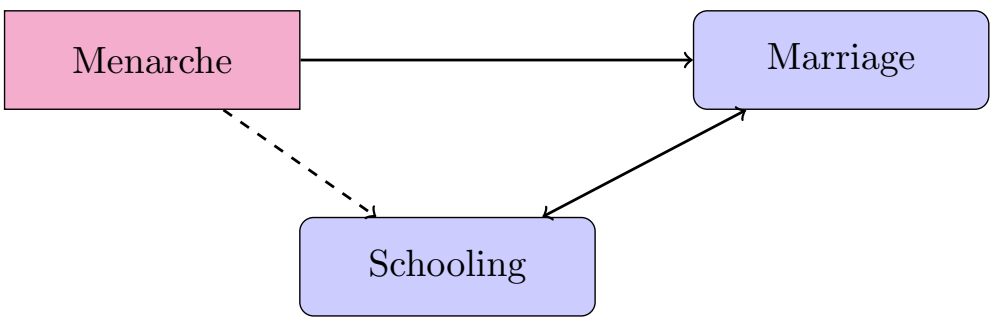

Figure 1 Menarche and Enrollment Choice. For girls in the early menarche group, menarche affects enrollment through constraint effects, but also through direct effects. For girls in the late menarche group, menarche affects enrollment through constraint effect, but also through indirect effects.

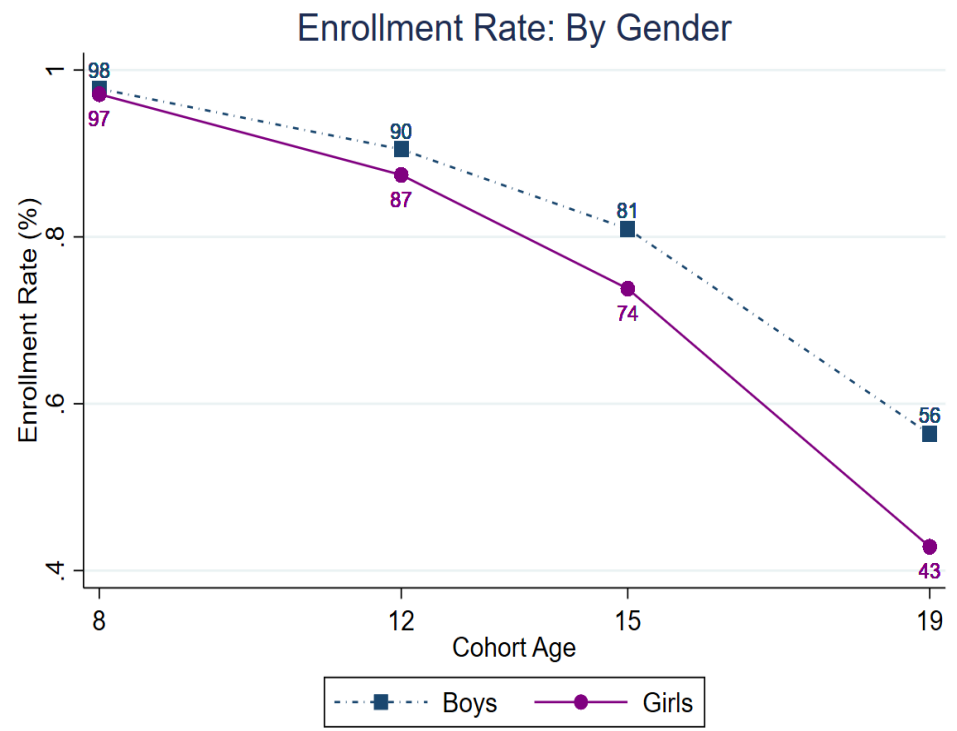

Figure 2 Enrollment Rate by gender. Data are taken from the Young Lives study. The solid (blue) line represents the trends in enrollment rate for boys and the dashed (blue) line represents the trends in enrollment rate for girls. 


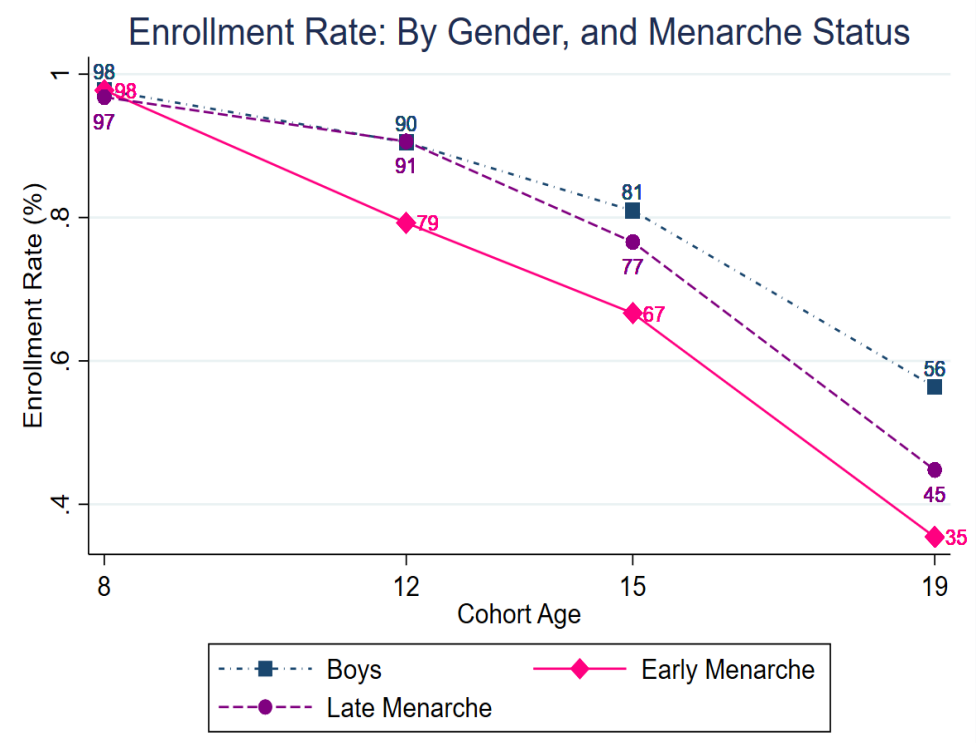

Figure 3 Enrollment Rate by Gender and Menarche Status. Data are taken from the Young Lives study. The dash-dotted (blue) line represents the trends in enrollment rate for boys, the dashed (purple) line represents the trends in enrollment rate for girls in the late menarche group and the solid (pink) line represents the trends in enrollment rate for girls in early menarche group.

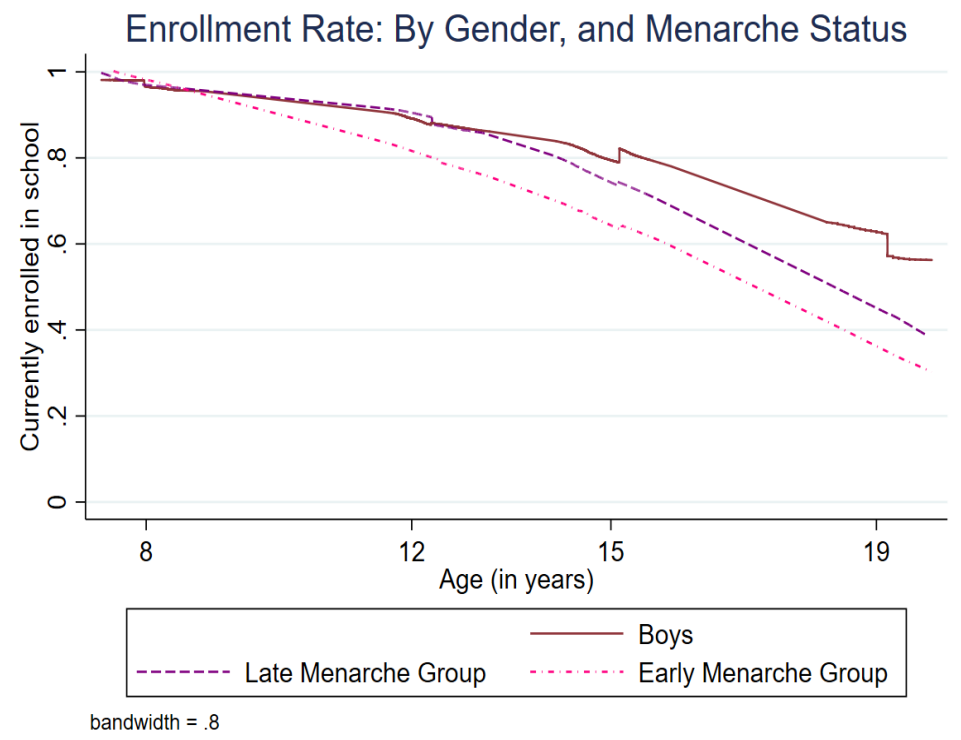

Figure 4 Enrollment Rate by Gender and Menarche Status - locally weighted regression. Data are taken from the Young Lives study. The solid (red) line represents the trends in enrollment rate for boys, the dashed (purple) line represents the trends in enrollment rate for girls in the late menarche group and the dash-dotted (pink) line represents the trends in enrollment rate for girls in early menarche group. 


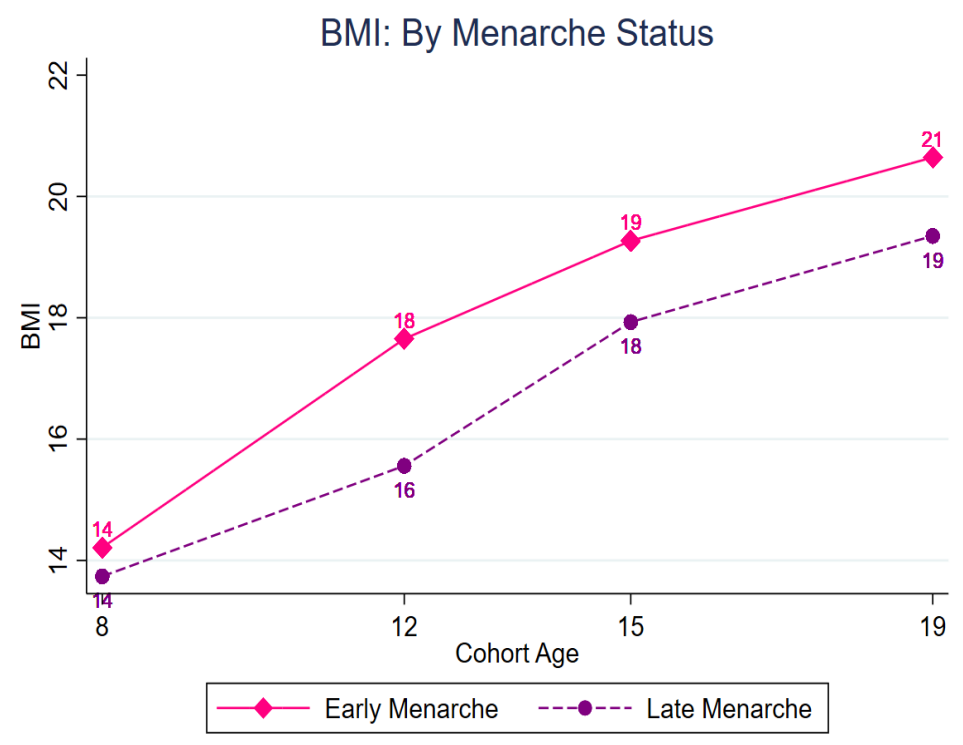

Figure 5 BMI by Menarche Status. Data are taken from the Young Lives study. The solid (pink) line represents the trends in BMI for girls in the early menarche group and the dashed (purple) line represents the trends in BMI for girls in the late menarche group.

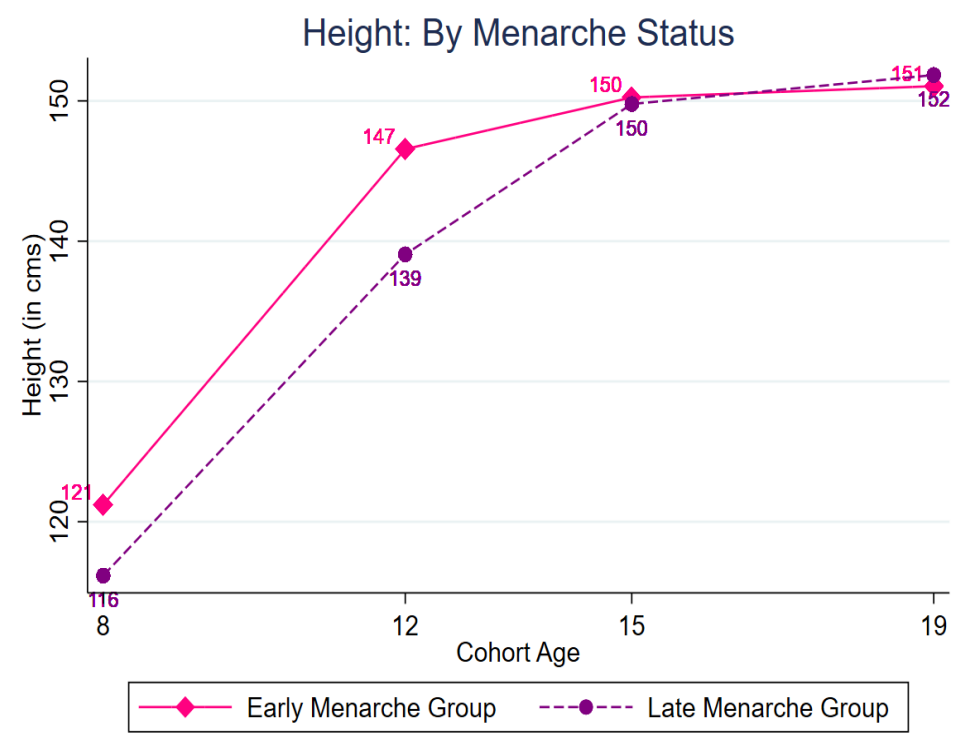

Figure 6 Height by Menarche Status. Data are taken from the Young Lives study. The solid (pink) line represents the trends in height (in centimeters) for girls in the early menarche group and the dashed (purple) line represents the trends in height (in centimeters) for girls in the late menarche group. 


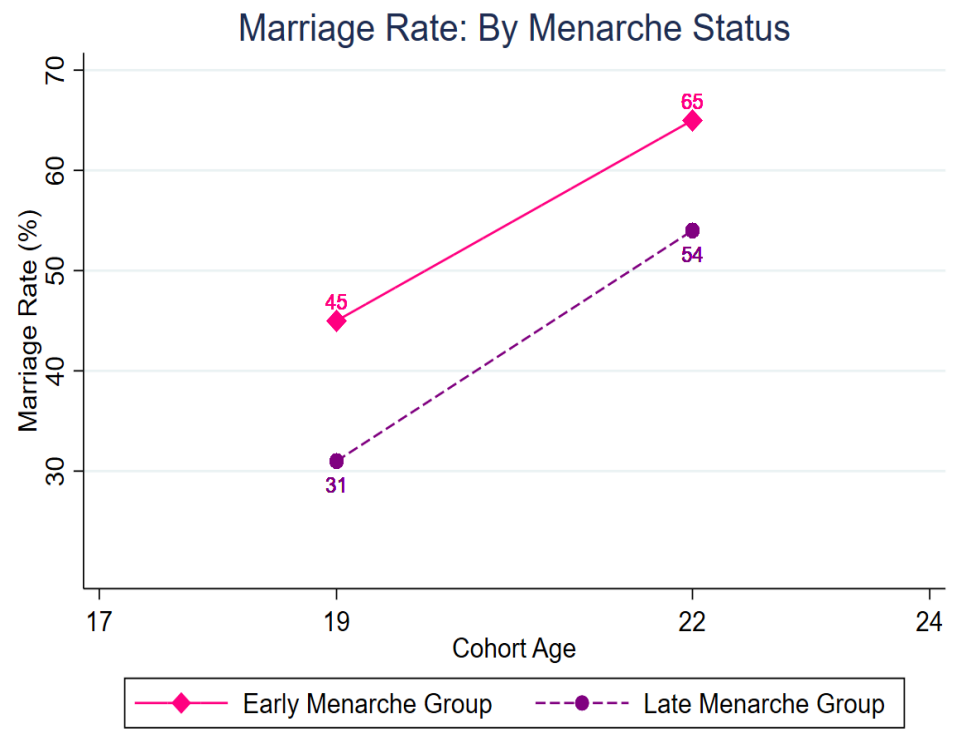

Figure 7 Marriage Rate by Menarche Status. Data are taken from the Young Lives study. The solid (pink) line represents the trends in marriage rate for girls in the early menarche group and the dashed (purple) line represents the trends in marriage rate for girls in the late menarche group. Both the lines describe trends the ages of nineteen and twenty-two.

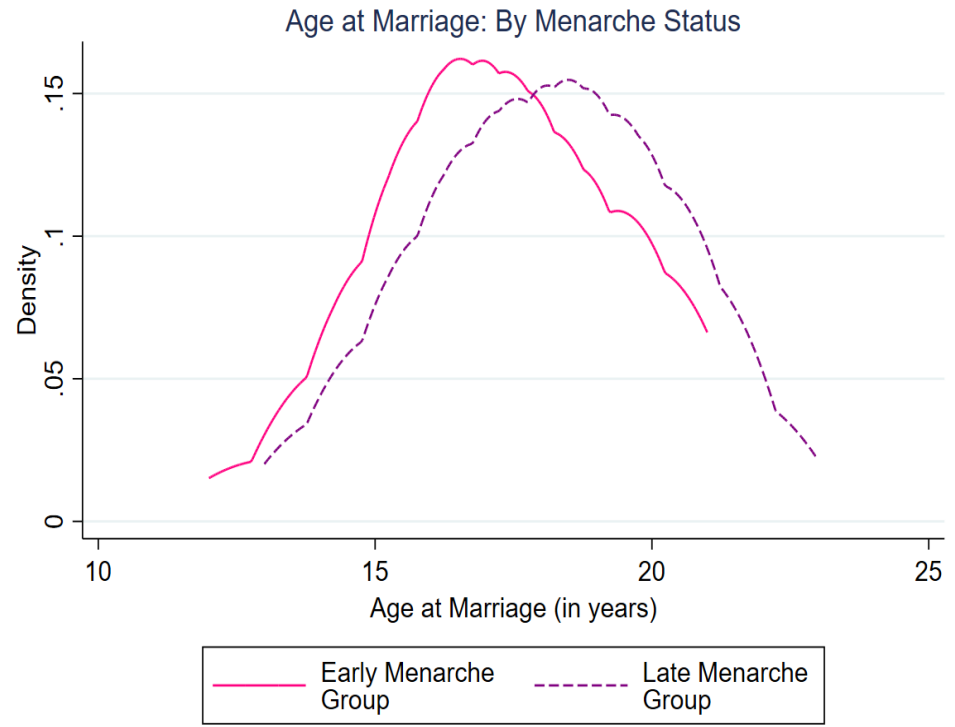

Figure 8 Age at Marriage by Menarche Status. Data are taken from the Young Lives study. The solid (pink) line represents the trends in age at marriage for girls in the early menarche group and the dashed (purple) line represents the trends in age at marriage for girls in the late menarche group. 


\section{Tables}

Table 1 Sample Characteristics in Round 1

\begin{tabular}{llllll}
\hline & Early Menarche & Late Menarche & Boys & \multicolumn{2}{c}{ Difference } \\
\hline & $(1)$ & $(2)$ & $(3)$ & $(1)-(2)$ & $(1)-(3)$ \\
\hline Household size & 5.32 & 5.62 & 5.56 & 0.30 & -0.24 \\
Wealth index & 0.43 & 0.40 & 0.41 & 0.03 & 0.02 \\
Literate mother & 0.27 & 0.21 & 0.21 & 0.06 & $0.06^{*}$ \\
Age of the household head & 39.84 & 40.51 & 40.00 & -0.67 & -0.15 \\
Experience of health shocks & 0.27 & 0.30 & 0.34 & -0.03 & -0.07 \\
Speaks Telugu & 0.86 & 0.85 & 0.83 & 0.01 & 0.03 \\
Number of older siblings & 0.91 & 1.07 & 1.16 & -0.16 & $-0.25^{* *}$ \\
Number of younger siblings & 0.69 & 0.80 & 0.67 & -0.11 & 0.02 \\
Number of older brothers & 0.66 & 0.61 & 0.72 & 0.05 & -0.06 \\
Number of older sisters & 0.42 & 0.67 & 0.72 & $-0.24^{* *}$ & $-0.30^{* *}$ \\
Raven's test score at age 8 & 23.37 & 22.83 & 22.97 & 0.54 & 0.40 \\
BMI at age 8 & 14.21 & 13.74 & 13.99 & $0.48^{* * *}$ & 0.22 \\
Height at age 8 & 121.21 & 116.16 & 118.56 & $5.05^{* * *}$ & $2.65^{* * *}$ \\
Weight at age 8 & 20.96 & 18.57 & 19.70 & $2.39^{* * *}$ & $1.26^{* * *}$ \\
Enrollment rate & 97.78 & 96.79 & 98.14 & 0.99 & -0.36 \\
\hline
\end{tabular}


Table 2 Enrolment Across Rounds 1 and 2 for Girls in the Early Menarche Group

\begin{tabular}{|c|c|c|c|c|c|c|}
\hline & \multicolumn{3}{|c|}{ vs Late Menrache Girls } & \multicolumn{3}{|c|}{ vs Boys } \\
\hline & (1) & $(2)$ & $(3)$ & (4) & $(5)$ & (6) \\
\hline Early menarche & $\begin{array}{c}0.010 \\
(0.011)\end{array}$ & $\begin{array}{c}0.018 \\
(0.019)\end{array}$ & $\begin{array}{c}0.026 \\
(0.022)\end{array}$ & $\begin{array}{c}-0.004 \\
(0.014)\end{array}$ & $\begin{array}{c}-0.003 \\
(0.014)\end{array}$ & $\begin{array}{l}-0.005 \\
(0.014)\end{array}$ \\
\hline Round 2 & $\begin{array}{c}-0.062^{* *} \\
(0.022)\end{array}$ & $\begin{array}{l}-0.035 \\
(0.031)\end{array}$ & $\begin{array}{l}-0.034 \\
(0.030)\end{array}$ & $\begin{array}{c}-0.078^{* * *} \\
(0.014)\end{array}$ & $\begin{array}{c}-0.043^{* *} \\
(0.017)\end{array}$ & $\begin{array}{c}-0.048^{* *} \\
(0.018)\end{array}$ \\
\hline Early menarche X Round 2 & $\begin{array}{c}-0.123^{* *} \\
(0.032)\end{array}$ & $\begin{array}{c}-0.121^{* * *} \\
(0.031)\end{array}$ & $\begin{array}{c}-0.122^{* * *} \\
(0.031)\end{array}$ & $\begin{array}{c}-0.107^{* *} \\
(0.038)\end{array}$ & $\begin{array}{c}-0.111^{* *} \\
(0.037)\end{array}$ & $\begin{array}{c}-0.111^{* *} \\
(0.037)\end{array}$ \\
\hline Observations & 1017 & 1013 & 1013 & 1240 & 1234 & 1234 \\
\hline$R^{2}$ & 0.0494 & 0.106 & 0.162 & 0.0555 & 0.100 & 0.128 \\
\hline Control_average & 0.906 & 0.906 & 0.906 & 0.903 & 0.903 & 0.903 \\
\hline Cluster_FE & No & No & Yes & No & No & Yes \\
\hline Controls & No & Yes & Yes & No & Yes & Yes \\
\hline
\end{tabular}

Note: This table reports the results from difference-in-differences specification (see Equation 5.1) for comparisons that span the first and the second survey round. Controls include household size, caste, sex of the household head, wealth index, mom's literacy status, age of the head of the household, indicator of whether the child speaks the majority language, number of younger siblings, number of older siblings, number of older sisters, number of older brothers, test scores at age eight, weight at age eight, and BMI at age eight. Sampling-site fixed effects are included. Robust standard errors clustered at the level of the sampling site are reported.

* Significant at $10 \%$;* Significant at $5 \%$; *** Significant at $1 \%$. 
Table 3 Enrolment Across Rounds 1 and 2 for Girls in the Late Menarche Group

\begin{tabular}{lccc}
\hline & \multicolumn{3}{c}{ vs Boys } \\
\cline { 2 - 4 } & $(1)$ & $(2)$ & $(3)$ \\
\hline Late menarche & -0.014 & -0.014 & -0.020 \\
& $(0.009)$ & $(0.010)$ & $(0.012)$ \\
Round 2 & $-0.078^{* * *}$ & $-0.061^{* *}$ & $-0.063^{* *}$ \\
& $(0.014)$ & $(0.017)$ & $(0.018)$ \\
Late menarche X Round 2 & 0.017 & 0.012 & 0.012 \\
& $(0.023)$ & $(0.024)$ & $(0.024)$ \\
\hline Observations & 1717 & 1707 & 1707 \\
$R^{2}$ & 0.0228 & 0.0611 & 0.0857 \\
Control_average & 0.903 & 0.903 & 0.903 \\
Cluster_FE & No & No & Yes \\
Controls & No & Yes & Yes \\
\hline
\end{tabular}

Note: This table reports the results from difference-in-differences specification (see Equation 5.1) for comparisons that span the first and the second survey round. Controls include household size, caste, sex of the household head, wealth index, mom's literacy status, age of the head of the household, indicator of whether the child speaks the majority language, number of younger siblings, number of older siblings, number of older sisters, number of older brothers, test scores at age eight, weight at age eight, and BMI at age eight. Sampling-site fixed effects are included. Robust standard errors clustered at the level of the sampling site are reported.

* Significant at $10 \% ; * *$ Significant at $5 \% ; * * *$ Significant at $1 \%$. 
Table 4 Tests for Parallel Trends

\begin{tabular}{lcccc}
\hline & $\begin{array}{c}\text { Girls in the } \\
\text { Early Menarche } \\
\text { Group vs Boys }\end{array}$ & $\begin{array}{c}\text { Early vs Late } \\
\text { Menarche } \\
\text { Groups }\end{array}$ \\
\cline { 2 - 3 } & $(1)$ & $(2)$ & $(3)$ \\
\hline \hline Specification: OLS & & & \\
\hline \hline Early menarche X Round 3 & -0.037 & & \\
& $(0.039)$ & & \\
Early menarche X Round 4 & & -0.051 & 0.017 \\
& & $(0.050)$ & $(0.042)$ \\
\hline \hline Specification: Logit & & & \\
\hline \hline Early menarche X Round 3 & 0.121 & & \\
& $(0.219)$ & & \\
Early menarche X Round 4 & & -0.111 & 0.040 \\
& & $(0.276)$ & $(0.236)$ \\
\hline Control_average & 0.808 & 0.561 & 0.448 \\
Cluster_FE & Yes & Yes & Yes \\
Controls & Yes & Yes & Yes \\
\hline
\end{tabular}

Note: This table reports the results from difference-in-differences specification (see Equation 5.1) for comparisons that span the first and the second survey round. Controls include household size, caste, sex of the household head, wealth index, mom's literacy status, age of the head of the household, indicator of whether the child speaks the majority language, number of younger siblings, number of older siblings, number of older sisters, number of older brothers, test scores at age eight, weight at age eight, and BMI at age eight. Sampling-site fixed effects are included. Robust standard errors clustered at the level of the sampling site are reported.

* Significant at $10 \%$;* Significant at $5 \%$; *** Significant at $1 \%$. 
Table 5 Normalized Test Scores in Round 2

\begin{tabular}{|c|c|c|c|c|}
\hline & \multicolumn{2}{|c|}{ PPVT } & \multicolumn{2}{|c|}{ Mathematics } \\
\hline & (1) & $(2)$ & $(3)$ & (4) \\
\hline & $\begin{array}{l}\text { vs Late } \\
\text { Menarche } \\
\text { Group }\end{array}$ & vs Boys & $\begin{array}{l}\text { vs Late } \\
\text { Menarche } \\
\text { Group }\end{array}$ & vs Boys \\
\hline Early menarche & $\begin{array}{c}0.072 \\
(0.068)\end{array}$ & $\begin{array}{c}-0.022 \\
(0.070)\end{array}$ & $\begin{array}{l}0.121^{*} \\
(0.072)\end{array}$ & $\begin{array}{c}0.020 \\
(0.087)\end{array}$ \\
\hline Observations & 497 & 601 & 498 & 610 \\
\hline$R^{2}$ & 0.396 & 0.387 & 0.449 & 0.410 \\
\hline Control_average & -0.0983 & 0.0585 & -0.0607 & 0.0470 \\
\hline Cluster_FE & Yes & Yes & Yes & Yes \\
\hline Controls & Yes & Yes & Yes & Yes \\
\hline Late menarche & & $\begin{array}{c}-0.148^{* *} \\
(0.051)\end{array}$ & & $\begin{array}{c}-0.117 \\
(0.069) \\
\end{array}$ \\
\hline Observations & & 832 & & 842 \\
\hline$R^{2}$ & & 0.364 & & 0.378 \\
\hline Control_average & & 0.06 & & 0.04 \\
\hline Girls & & $\begin{array}{c}-0.130^{* *} \\
(0.046)\end{array}$ & & $\begin{array}{c}-0.079 \\
(0.068)\end{array}$ \\
\hline Observations & & 965 & & 975 \\
\hline$R^{2}$ & & 0.371 & & 0.390 \\
\hline Control_average & & 0.06 & & 0.05 \\
\hline Cluster_FE & Yes & Yes & Yes & Yes \\
\hline Controls & Yes & Yes & Yes & Yes \\
\hline
\end{tabular}

Note: This table reports the results from single-difference specification (see Equation 5.3). Controls include household size, caste, sex of the household head, wealth index, mom's literacy status, age of the head of the household, indicator of whether the child speaks the majority language, number of younger siblings, number of older siblings, number of older sisters, number of older brothers, test scores at age eight, weight at age eight, and BMI at age eight. Sampling-site fixed effects are included. Robust standard errors clustered at the level of the sampling site are reported.

* Significant at $10 \% ; * *$ Significant at $5 \% ; * * *$ Significant at $1 \%$. 
Table 6 Enrolment Across Rounds 2 and 3 for Girls in the Late Menarche Group

\begin{tabular}{|c|c|c|c|c|c|c|}
\hline & \multicolumn{3}{|c|}{ vs Early Menrache Girls } & \multicolumn{3}{|c|}{ vs Boys } \\
\hline & $(1)$ & $(2)$ & $(3)$ & $(4)$ & $(5)$ & (6) \\
\hline \multirow[t]{2}{*}{ Late menarche } & $0.114^{* *}$ & $0.088^{* *}$ & $0.073^{*}$ & 0.003 & -0.009 & -0.021 \\
\hline & $(0.032)$ & $(0.032)$ & $(0.039)$ & $(0.027)$ & $(0.028)$ & $(0.032)$ \\
\hline \multirow[t]{2}{*}{ Round 3} & $-0.126^{* *}$ & $-0.137^{* *}$ & $-0.140^{* *}$ & $-0.095^{* * *}$ & $-0.108^{* * *}$ & $-0.110^{* * *}$ \\
\hline & $(0.039)$ & $(0.042)$ & $(0.043)$ & $(0.016)$ & $(0.019)$ & $(0.019)$ \\
\hline \multirow[t]{2}{*}{ Late menarche X Round 3} & -0.014 & -0.016 & -0.014 & $-0.045^{*}$ & $-0.047^{* *}$ & $-0.047^{* *}$ \\
\hline & $(0.043)$ & $(0.046)$ & $(0.046)$ & $(0.022)$ & $(0.022)$ & $(0.022)$ \\
\hline Observations & 1003 & 995 & 995 & 1700 & 1681 & 1681 \\
\hline$R^{2}$ & 0.0445 & 0.154 & 0.252 & 0.0271 & 0.102 & 0.151 \\
\hline Control_average & 0.667 & 0.667 & 0.667 & 0.808 & 0.808 & 0.808 \\
\hline Cluster_FE & No & No & Yes & No & No & Yes \\
\hline Controls & No & Yes & Yes & No & Yes & Yes \\
\hline
\end{tabular}

Note: This table reports the results from difference-in-differences specification (see Equation 5.1) for comparisons that span the second and the third survey round. Controls include household size, caste, sex of the household head, wealth index,mom's literacy status, age of the head of the household, indicator of whether the child speaks the majority language, number of younger siblings, number of older siblings, number of older brothers, number of older sisters, test scores at age eight, weight at age eight, and BMI at age eight. Sampling-site fixed effects are included. Robust standard errors clustered at the level of the sampling site are reported.

* Significant at $10 \%$; ** Significant at $5 \%$; *** Significant at $1 \%$.

Table 7 Markers of Gender Performane, by Caste

\begin{tabular}{lcccc}
\hline & $(1)$ & $\begin{array}{c}(2) \\
\text { Can go to: }\end{array}$ & $\begin{array}{c}(3) \\
\text { Can go to: } \\
\text { Kirana shop }\end{array}$ & $\begin{array}{c}(4) \\
\text { Can go to: } \\
\text { Friend's house }\end{array}$ \\
\hline Scheduled caste & $-0.046^{*}$ & 0.039 & $0.051^{* *}$ & 0.038 \\
& $(0.025)$ & $(0.035)$ & $(0.022)$ & $(0.036)$ \\
\hline Observations & 1774 & 1774 & 1774 & 1774 \\
$R^{2}$ & 0.288 & 0.216 & 0.209 & 0.229 \\
Control_average & 0.145 & 0.588 & 0.802 & 0.651 \\
PSU_FE & Yes & Yes & Yes & Yes \\
Controls & Yes & Yes & Yes & Yes \\
\hline
\end{tabular}

Note: This table reports the results on the association between markers of gender performance and caste for the state of Andhra Pradesh using the second round of the nationally representative IHDS Survey. Controls include an indicator for land ownership, logged per capita consumption expenditure, age, age squared, an indicator for whether the woman married before eighteen, number of household members and number of married women between the ages of fifteen and forty-nine. Primary Sampling-site fixed effects are included. Robust standard errors clustered at the level of the primary sampling unit are reported.

* Significant at $10 \%$;* Significant at $5 \%$; *** Significant at $1 \%$. 
Table 8 Impact of Early Menarche of Enrollment, by Caste and Local Safety Environment

\begin{tabular}{lcc}
\hline & $(1)$ & $\begin{array}{c}(2) \\
\text { Average Perception } \\
\text { of Safety }\end{array}$ \\
\hline Early menarche X Round 2 & Scheduled Castes & -0.065 \\
Early Menarche X Round 2 X Non-SC & -0.014 & $(0.051)$ \\
& $(0.063)$ & \\
Early Menarche X Round 2 X Lower Perceived Safety & $-0.136^{\dagger}$ & $-0.124^{\ddagger}$ \\
& & $(0.085)$ \\
Observations & & 1013 \\
$R^{2}$ & 1013 & 0.168 \\
Control_average & 0.167 & 0.906 \\
Cluster_FE & 0.906 & Yes \\
Controls & Yes & Yes \\
\hline
\end{tabular}

Note: This table reports the results from a triple-difference specification (see Equation 5.2) for comparisons that span the first and the second survey rounds. Column (1) reports results when the difference-in-differences specification is interacted with the presence of a lower level of crime in the community, Column (2) reports results when the difference-in-differences specification is interacted with if the girl resides in a community with police station, and Column (3) reports results when the difference-in-differences specification is interacted with an indicator that the average community level perceived safety among boys is less than the median. Controls include household size, caste, sex of the household head, wealth index,mom's literacy status, age of the head of the household, indicator of whether the child speaks the majority language, number of younger siblings, number of older siblings, number of older brothers, number of older sisters, test scores at age eight, weight at age eight, and BMI at age eight. Sampling-site fixed effects are included. Robust standard errors clustered at the level of the sampling site are reported.

* Significant at $10 \%$;* Significant at $5 \%$; ** Significant at $1 \%$. $\dagger$ p-value: $0.12 ; \ddagger$ p-value: 0.18 . 
Table 9 Impact of Early Menarche of Enrollment, by Average Local Wages for Female Dominated Professions

\begin{tabular}{lcc}
\hline & $(1)$ & $(2)$ \\
& Teachers' Wages & Nurses' Wages \\
\hline Early menarche X Round 2 & $-0.079^{* * *}$ & $-0.054^{*}$ \\
& $(0.020)$ & $(0.026)$ \\
Early Menarche X Round 2 X Lower Teacher Wages & -0.089 & \\
& $(0.062)$ & $-0.107^{*}$ \\
Early Menarche X Round 2 X Lower Nurse Wages & & $(0.055)$ \\
& & 1013 \\
Observations & 1013 & 0.177 \\
$R^{2}$ & 0.168 & 0.906 \\
Control_average & 0.906 & Yes \\
Cluster_FE & Yes & Yes \\
Controls & Yes & \\
\hline
\end{tabular}

Note: This table reports the results from a triple-difference specification (see Equation 5.2) for comparisons that span the first and the second survey rounds. Column (1) reports results when the difference-in-differences specification is interacted with the presence of a lower level of crime in the community, Column (2) reports results when the difference-in-differences specification is interacted with if the girl resides in a community with police station, and Column (3) reports results when the difference-in-differences specification is interacted with an indicator that the average community level perceived safety among boys is less than the median. Controls include household size, caste, sex of the household head, wealth index,mom's literacy status, age of the head of the household, indicator of whether the child speaks the majority language, number of younger siblings, number of older siblings, number of older brothers, number of older sisters, test scores at age eight, weight at age eight, and BMI at age eight. Sampling-site fixed effects are included. Robust standard errors clustered at the level of the sampling site are reported.

* Significant at $10 \%$; ** Significant at $5 \%$; ** Significant at $1 \%$. $\dagger$ p-value: 0.16 . 
Table 10 Girls in the Early and the Late Menarche Group- BMI, Height and Caretaker's Perception of Child's Health

\begin{tabular}{lccc}
\hline & & & $\begin{array}{c}\text { Caretaker's Perception } \\
\text { of Child's Health } \\
\text { Relative to Peers }\end{array}$ \\
\cline { 2 - 4 } & $(1)$ & $(2)$ & $(3)$ \\
\hline Early menarche & $0.406^{* *}$ & $4.477^{* * *}$ & -0.063 \\
Round 2 & $(0.131)$ & $(0.543)$ & $(0.042)$ \\
& $1.628^{* * *}$ & $22.483^{* * *}$ & -0.032 \\
Early menarche X Round 2 & $(0.134)$ & $(1.187)$ & $(0.082)$ \\
& $1.612^{* * *}$ & $2.427^{* *}$ & $0.153^{* *}$ \\
Observations & $(0.248)$ & $(0.928)$ & $(0.072)$ \\
$R^{2}$ & 1003 & 1007 & 1014 \\
Control_average & 0.403 & 0.667 & 0.102 \\
Individual_FE & 15.56 & 139.1 & 0.425 \\
Controls & & & Yes \\
\hline
\end{tabular}

Note: This table reports the results from difference-in-differences specification (see Equation 5.1). Controls include household size, caste, sex of the household head, wealth index,mom's literacy status, age of the head of the household, indicator of whether the child speaks the majority language, number of younger siblings, number of older siblings, number of older sisters, number of older brothers, test scores at age eight, weight at age eight, and BMI at age eight. Sampling-site fixed effects are included. Robust standard errors clustered at the level of the sampling site are reported.

* Significant at $10 \%$; ** Significant at $5 \%$; ** Significant at $1 \%$. 
Table 11 Other Investments in Girls in the Early Menarche Group in Round 2

\begin{tabular}{lccccccc}
\hline & \multicolumn{7}{c}{ Food Intake (last seven days) } \\
& $\begin{array}{l}\text { Exp. } \\
\text { (in rupees) }\end{array}$ & Cereal & Roots & Legumes & Milk & Eggs & Meat \\
\cline { 2 - 8 } & $(1)$ & $(2)$ & $(3)$ & $(4)$ & $(5)$ & $(6)$ & $(7)$ \\
\hline Early menarche & 969.268 & 0.029 & -0.037 & -0.037 & $0.068^{*}$ & 0.007 & 0.037 \\
& $(1785.812)$ & $(0.035)$ & $(0.046)$ & $(0.054)$ & $(0.038)$ & $(0.033)$ & $(0.031)$ \\
\hline Observations & 501 & 507 & 507 & 507 & 507 & 486 & 478 \\
$R^{2}$ & 0.128 & 0.255 & 0.208 & 0.224 & 0.0845 & 0.117 & 0.136 \\
Control_average & 7559.8 & 0.251 & 0.380 & 0.647 & 0.171 & 0.0922 & 0.0627 \\
Cluster_FE & Yes & Yes & Yes & Yes & Yes & Yes & Yes \\
Controls & Yes & Yes & Yes & Yes & Yes & Yes & Yes \\
\hline
\end{tabular}

Note: This table reports the results from single-difference specification (see Equation 5.3) using data from the second survey round. Controls include household size, caste, sex of the household head, wealth index,mom's literacy status, age of the head of the household, indicator of whether the child speaks the majority language, number of younger siblings, number of older siblings, number of older sisters, number of older brothers, test scores at age eight, weight at age eight, and BMI at age eight. Sampling-site fixed effects are included. Robust standard errors clustered at the level of the sampling site are reported.

* Significant at $10 \%$; ** Significant at $5 \%$; ** Significant at $1 \%$. 
Table 12 Normalized Test Scores of the Girls in the Early Menarche Group versus Other Children Across Rounds 2 and 3

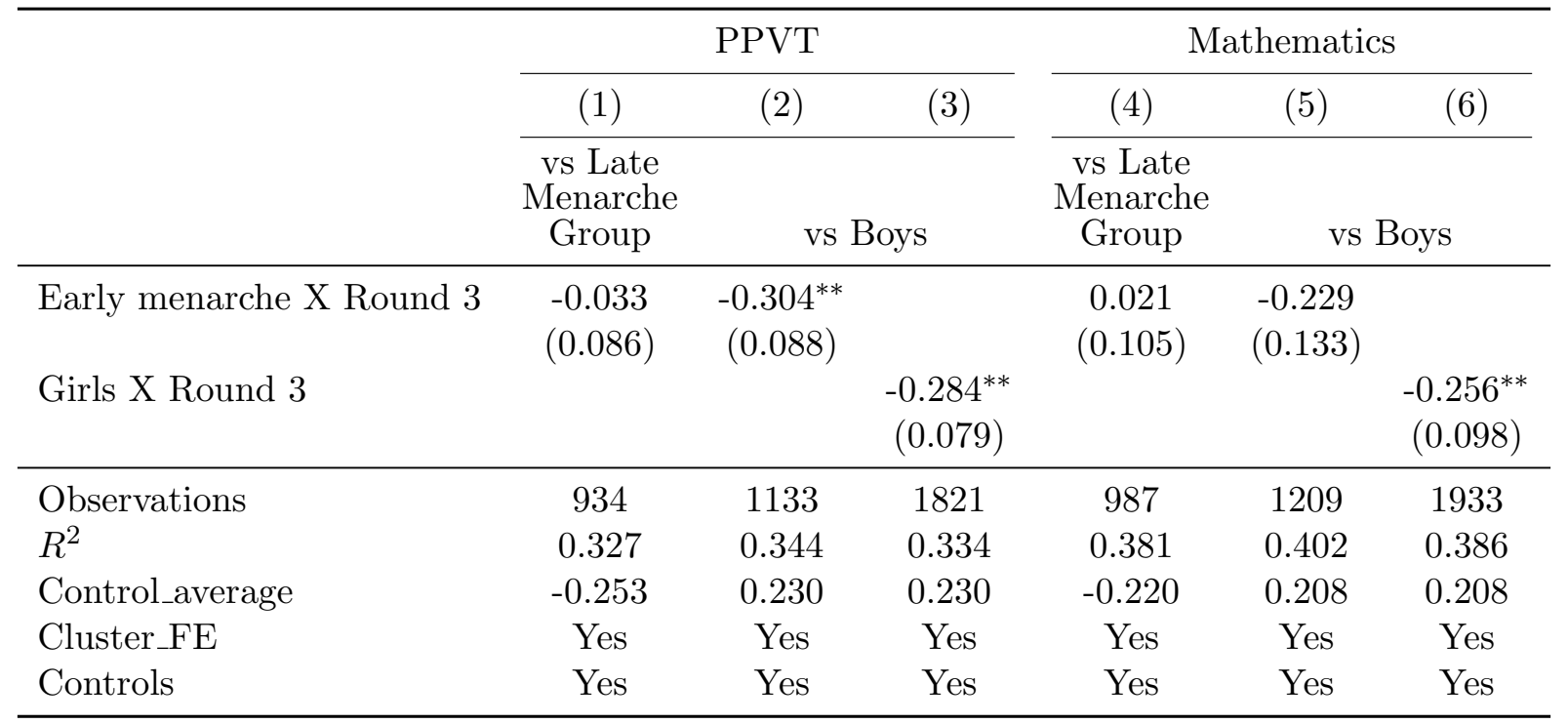

Note: This table reports the results from difference-in-differences specification (see Equation 5.1). Controls include enrolment status of the child, household size, caste, sex of the household head, wealth index,mom's literacy status, age of the head of the household, indicator of whether the child speaks the majority language, number of younger siblings, number of older siblings, test scores at age eight, weight at age eight, and BMI at age eight. Sampling-site fixed effects are included. Robust standard errors clustered at the level of the sampling site are reported.

* Significant at $10 \%$; ** Significant at 5\%; *** Significant at $1 \%$.

Table 13 Time Use Patterns, Proportion of Time in the Day

\begin{tabular}{lccccccc}
\hline & $(1)$ & $(2)$ & $(3)$ & $(4)$ & $(5)$ & $(6)$ & $(7)$ \\
& Housework & Household Chores & Care & Sleep & Play & School & Study \\
\hline Early menarche & $0.019^{* *}$ & 0.012 & 0.001 & 0.006 & 0.000 & $-0.028^{*}$ & $-0.014^{* *}$ \\
& $(0.009)$ & $(0.008)$ & $(0.003)$ & $(0.006)$ & $(0.011)$ & $(0.015)$ & $(0.005)$ \\
\hline Observations & 483 & 483 & 483 & 483 & 483 & 496 & 483 \\
$R^{2}$ & 0.125 & 0.202 & 0.159 & 0.342 & 0.192 & 0.257 & 0.298 \\
Control_average & 0.0111 & 0.0488 & 0.0114 & 0.396 & 0.166 & 0.269 & 0.0844 \\
Cluster_FE & Yes & Yes & Yes & Yes & Yes & Yes & Yes \\
Controls & Yes & Yes & Yes & Yes & Yes & Yes & Yes \\
\hline
\end{tabular}

Note: This table reports the results from single-difference specification (see Equation 5.3) for data from the second survey round when children were twelve. Controls include household size, caste, sex of the household head, wealth index,mom's literacy status, age of the head of the household, indicator of whether the child speaks the majority language, number of younger siblings, number of older siblings, number of older brothers, number of older sisters, test scores at age eight, weight at age eight, and BMI at age eight. Sampling-site fixed effects are included. Robust standard errors clustered at the level of the sampling site are reported.

* Significant at 10\%; ** Significant at 5\%; *** Significant at $1 \%$. 
Table 14 Time Use Patterns of Older Siblings, Proportion of Time in the Day

\begin{tabular}{lccccccc}
\hline & $(1)$ & $(2)$ & $(3)$ & $(4)$ & $(5)$ & $(6)$ & $(7)$ \\
& Work & Household Chores & Care & Sleep & Play & School & Study \\
\hline Early menarche & 0.002 & -0.004 & -0.000 & -0.007 & -0.013 & -0.014 & -0.016 \\
& $(0.012)$ & $(0.004)$ & $(0.002)$ & $(0.020)$ & $(0.020)$ & $(0.016)$ & $(0.012)$ \\
\hline Observations & 496 & 496 & 496 & 496 & 496 & 496 & 496 \\
$R^{2}$ & 0.0807 & 0.141 & 0.198 & 0.174 & 0.0794 & 0.170 & 0.0678 \\
Control_average & 0.0155 & 0.0211 & 0.00561 & 0.304 & 0.158 & 0.196 & 0.0577 \\
Cluster_FE & Yes & Yes & Yes & Yes & Yes & Yes & Yes \\
Controls & Yes & Yes & Yes & Yes & Yes & Yes & Yes \\
\hline
\end{tabular}

Note: This table reports the results from single-difference specification (see Equation 5.3) for data from the second survey round when children were twelve. Controls include household size, caste, sex of the household head, wealth index,mom's literacy status, age of the head of the household, indicator of whether the child speaks the majority language, number of younger siblings, number of older siblings, number of older brothers, number of older sisters, test scores at age eight, weight at age eight, and BMI at age eight. Sampling-site fixed effects are included. Robust standard errors clustered at the level of the sampling site are reported.

* Significant at $10 \% ; * *$ Significant at $5 \%$; ** Significant at $1 \%$.

Table 15 Time Use Patterns of Younger Siblings, Proportion of Time in the Day

\begin{tabular}{lccccccc}
\hline & $(1)$ & $(2)$ & $(3)$ & $(4)$ & $(5)$ & $(6)$ & $(7)$ \\
& Work & Household Chores & Care & Sleep & Play & School & Study \\
\hline Early menarche & 0.034 & 0.037 & 0.034 & 0.048 & 0.024 & 0.045 & 0.032 \\
& $(0.034)$ & $(0.034)$ & $(0.034)$ & $(0.028)$ & $(0.042)$ & $(0.030)$ & $(0.033)$ \\
\hline Observations & 403 & 403 & 403 & 403 & 403 & 403 & 403 \\
$R^{2}$ & 0.0866 & 0.0817 & 0.0810 & 0.128 & 0.0760 & 0.180 & 0.0995 \\
Control_average & 0.0155 & 0.0211 & 0.00561 & 0.304 & 0.158 & 0.196 & 0.0577 \\
Cluster_FE & Yes & Yes & Yes & Yes & Yes & Yes & Yes \\
Controls & Yes & Yes & Yes & Yes & Yes & Yes & Yes \\
\hline
\end{tabular}

Note: This table reports the results from single-difference specification (see Equation 5.3) for data from the second survey round. Controls include household size, caste, sex of the household head, wealth index,mom's literacy status, age of the head of the household, indicator of whether the child speaks the majority language, number of younger siblings, number of older siblings, test scores at age eight, weight at age eight, and BMI at age eight. Sampling-site fixed effects are included. Robust standard errors clustered at the level of the sampling site are reported. * Significant at $10 \%$; ** Significant at $5 \%$; *** Significant at $1 \%$. 
Table 16 Aspirations and Beliefs

\begin{tabular}{lccc}
\hline & $\begin{array}{c}(1) \\
\text { Aspiration: } \\
\text { Fulltime parent } \\
\text { or housewife }\end{array}$ & $\begin{array}{c}(2) \\
\text { Aspiration: } \\
\text { Attend college }\end{array}$ & $\begin{array}{c}(3) \\
\text { Aspirtation } \\
\text { likely to } \\
\text { be fulfilled }\end{array}$ \\
\hline Early menarche & -0.009 & -0.043 & $-0.064^{*}$ \\
& $(0.026)$ & $(0.045)$ & $(0.037)$ \\
Round 2 & $0.060^{* *}$ & & \\
& $(0.025)$ & & \\
Early menarche X Round 2 & $0.088^{* *}$ & & \\
& $(0.039)$ & & 0.230 \\
\hline Observations & 1014 & 507 & 0.861 \\
$R^{2}$ & 0.161 & 0.115 & Yes \\
Control_average & 0.107 & 0.738 & Yes \\
Cluster_FE & Yes & Yes & Yes \\
Controls & Yes & & \\
\hline
\end{tabular}

Note: Column (1) reports the results from difference-in-differences specification (see Equation 5.1) for comparisons that span the first and the second survey rounds. Columns (2) and (3) reports the results from single-difference specification (see Equation 5.3). Controls include household size, caste, sex of the household head, wealth index,mom's literacy status, age of the head of the household, indicator of whether the child speaks the majority language, number of younger siblings, number of older siblings, number of older brothers, number of older sisters, test scores at age eight, weight at age eight, and BMI at age eight. Sampling-site fixed effects are included. Robust standard errors clustered at the level of the sampling site are reported.

* Significant at 10\%; ** Significant at 5\%; *** Significant at 1\%. 
Table 17 Marital Timing

\begin{tabular}{|c|c|c|c|c|c|}
\hline & $\begin{array}{l}(1) \\
\text { Ever Married } \\
\text { at } 19\end{array}$ & $\begin{array}{c}(2) \\
\text { Ever Married } \\
\text { at } 22\end{array}$ & $\begin{array}{l}(3) \\
\text { Age }\end{array}$ & $\begin{array}{l}\text { (4) } \\
\text { Gap Between } \\
\text { Ages at Dropout } \\
\text { and Marriage }\end{array}$ & $\begin{array}{c}(5) \\
\text { Ever } \\
\text { Married }\end{array}$ \\
\hline Early menarche & $\begin{array}{c}0.114 \\
(0.072)\end{array}$ & $\begin{array}{c}0.112 \\
(0.076)\end{array}$ & $\begin{array}{c}-0.813^{* *} \\
(0.347)\end{array}$ & $\begin{array}{c}-0.878^{* *} \\
(0.365)\end{array}$ & $\begin{array}{c}0.128^{*} \\
(0.065)\end{array}$ \\
\hline Round 5 & & & & & $\begin{array}{c}0.201^{* * *} \\
(0.020)\end{array}$ \\
\hline Early menarche X Round 5 & & & & & $\begin{array}{l}-0.029 \\
(0.042)\end{array}$ \\
\hline Observations & 495 & 495 & 272 & 224 & 953 \\
\hline$R^{2}$ & 0.203 & 0.218 & 0.246 & 0.268 & 0.251 \\
\hline Control_average & 0.325 & 0.539 & 18.18 & 5.371 & 0.461 \\
\hline Cluster_FE & Yes & Yes & Yes & Yes & Yes \\
\hline Controls & Yes & Yes & Yes & Yes & Yes \\
\hline
\end{tabular}

Note: Columns (1)-(4) of this table reports the results from single-difference specification (see Equation 5.3) and column (4) reports results from a difference-in-differences specification (see Equation 5.2). Controls include girl's natal home's household size, caste, sex of the household head, landholding in round 3, mom's literacy status, age of the head of the household, indicator of whether the girl speaks the majority language, number of younger siblings, number of older siblings, number of older brothers, number of older sisters, test scores at age eight, weight at age eight, and BMI at age eight. Sampling-site fixed effects are included. Robust standard errors clustered at the level of the sampling site are reported.

* Significant at $10 \%$; ** Significant at 5\%; *** Significant at $1 \%$. 
Table 18 Other Features of Marriage

\begin{tabular}{lcccc}
\hline & $\begin{array}{c}(1) \\
\text { Met on } \\
\text { the Day of } \\
\text { the Wedding }\end{array}$ & $\begin{array}{c}(2) \\
\text { Parents Chose } \\
\text { the Spouse }\end{array}$ & $\begin{array}{c}(3) \\
\text { Value on } \\
\text { Gifts Given } \\
\text { (in 100,000 rupees) }\end{array}$ & $\begin{array}{c}(4) \\
\begin{array}{c}\text { Spouse's } \\
\text { Education } \\
\text { (in years) }\end{array}\end{array}$ \\
\hline Early menarche & -0.065 & 0.023 & -0.411 & -0.693 \\
& $(0.082)$ & $(0.075)$ & $(1.095)$ & $(0.558)$ \\
\hline Observations & 272 & 272 & 267 & 224 \\
$R^{2}$ & 0.201 & 0.272 & 0.221 & 0.220 \\
Control_average & 0.422 & 0.395 & 3.258 & 3.258 \\
Cluster_FE & Yes & Yes & Yes & Yes \\
Controls & Yes & Yes & Yes & Yes \\
\hline
\end{tabular}

Note: This table reports the results from single-difference specification (see Equation 5.3).

Controls include girl's natal home's household size, caste, sex of the household head, landholding in round 3, mom's literacy status, age of the head of the household, indicator of whether the girl speaks the majority language, number of younger siblings, number of older siblings, number of older brothers, number of older sisters, test scores at age eight, weight at age eight, and BMI at age eight. Sampling-site fixed effects are included. Robust standard errors clustered at the level of the sampling site are reported.

* Significant at 10\%; ** Significant at 5\%; *** Significant at $1 \%$. 


\section{A Appendix}

\section{A.1 Context: State of Andhra Pradesh and the Sampling Strategy}

??

Andhra Pradesh (including the state of Telangana) is the fifth-largest state in India. In 2002, when the Young Lives study started in Andhra Pradesh, only $27 \%$ of the population was living in urban areas. While agriculture was important and contributed to $30 \%$ of the state domestic product, economic activity was increasingly shifting away from agriculture. In 2004-05, rural poverty rate was $11 \%$ while the urban poverty rate was $28 \%$. Andhra Pradesh is close to the all India averages on various measures of human development. In 2004-05, the Andhra Pradesh's infant mortality rate was 53 as opposed to 57 for the whole country. Average life expectancy in Andhra Pradesh was 63.9, while it was 65.4 in India. Adult literacy and enrollment rates were 50.9 and 87.6 in Andhra Pradesh, respectively, and 61.8 and 82.1 in India (Centre for Economic and Social Studies, 2007).

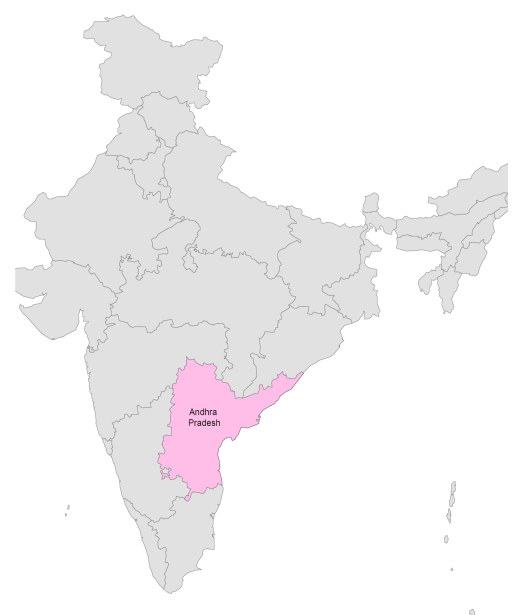

Figure A.1.1 Andhra Pradesh

Andhra Pradesh has three historically distinct sociocultural regions, Coastal Andhra, Rayalseema and Telangana (Figure A.1.2). These divisions are divided into twenty-three districts (Figure A.1.3). Each district composed of three to five divisions, and each division has ten-fifteen mandals. A mandal is the lowest administrative tier of the government of Andhra Pradesh.

The sample for the Young Lives study was drawn such that the three regions the region was well represented. In addition to the metropolitan city of Hyderabad, two districts from each region, one poor and one non-poor, were drawn. Next, from each district mandals were chosen to representative of key development indicators. These chosen mandals, along with three urban slums chosen from Hyderabad were the primary sampling units (sampling sites). From a list of villages that would have had at least fifty eight-year-olds and at least hundred one-year-olds, sample villages were randomly chosen from the selected sampling sites. 
Household covered by the Young Lives study are wealthier than the average household in Andhra Pradesh. A comparison with the households surveyed by the Demographic and Health Survey, 199899 reveals that the surveyed households also had a better access to services. Despite these biases, the sample covered by the Young Lives study captures the diversity of children in poor households in Andhra Pradesh.

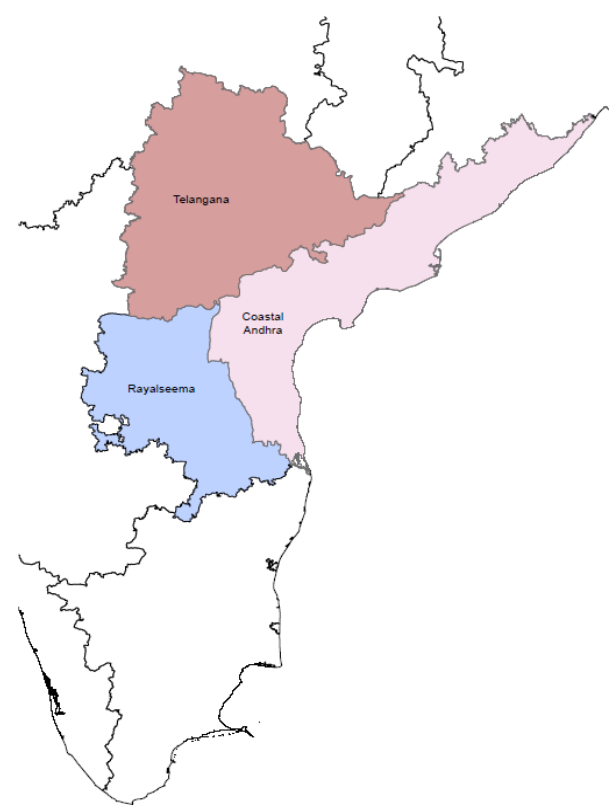

Figure A.1.2 Sociocultural Regions in Andhra Pradesh

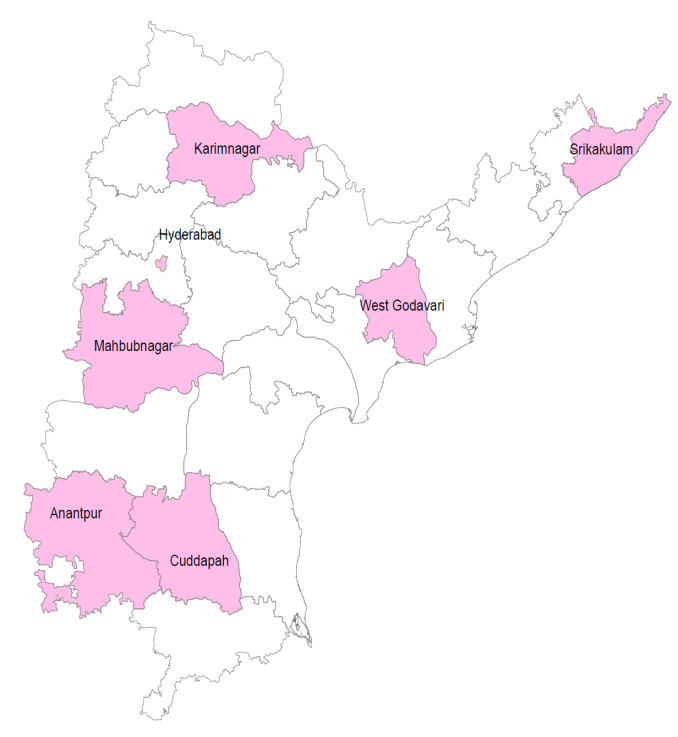

Figure A.1.3 Selected Districts in Andhra Pradesh

\section{References}

Centre for Economic and Social Studies. (2007). Human Development Report 2007. Retrieved from https://www . undp.org/content/dam/india/docs/human_revelop_report_ andhra_pradesh_2007_full_report.pdf 


\section{A.2 Evidence from Other Young Lives Countries}

This section describes and discusses the evidence on the effect of early menarche on enrollment in Peru and Vietnam, the other countries where the Young Lives study was conducted. In addition to India, Peru and Vietnam, the Young Lives study was also conducted in Ethiopia. However, only seventeen girls in Ethiopia had reached menarche by twelve as opposed to $35 \%$ girls in Peru and $22 \%$ girls in Vietnam. As is the case for the Indian cohort surveyed by the Young Lives study, girls in the early menarche group in both Peru and Vietnam are significantly taller than girls in the late menarche group. Girls in the early menarche group also have significantly higher BMI than girls in the late menarche group (Table A.2.1).

Table A.2.2 describes the results from various specifications of Equation 5.1 for Peru. Columns (1)-(3) compare girls in the early menarche group to girls in the late menarche group, while Columns (4)-(6) compare girls in the early menarche group to boys. In case of the former comparison, the strictest specification yields an effect of $-0.2 \%$ which statistically insignificant. When girls in the late menarche group are compared to boys, the effect of reaching menarche before twelve is only $-0.1 \%$ points.

Table A.2.3 describes the results from various specifications of Equation 5.1 for Vietnam. ${ }^{\text {a }}$ Columns (1)-(3) compare girls in the early menarche group to girls in the late menarche group, while Columns (4)-(6) compare girls in the early menarche group to boys. Surprisingly, girls in the early menarche have the lowest decrease in the enrollment rate across ages eight and twelve. When girls in the early menarche group are compared to the girls in the late menarche group, the estimated impact of reaching menarche before twelve is $4.8 \%$, or $5 \%$ of the age- and genderappropriate average enrollment rate of $95.3 \%$. When girls in the early menarche group are compared to boys, the estimate impact of reaching menarche before twelve is $3 \%$. Note that girls in the early menarche group are typically healthier than girls in the late menarche group. In Vietnam, this health advantage is reflected by the trends in enrollment rate.

\footnotetext{
${ }^{\text {a }}$ There is one difference in the empirical specification used to estimate the impact of early menarche for India, and the one used for Vietnam: instead of using children's test scores in Raven's test at age eight, indicators for whether children have problem while reading and writing and age appropriate text are included because the majority of children in Vietnam did not take the Raven's test.
} 


\section{Tables}

Table A.2.1 Difference Across Girls in the Early and the late Menrache Group, Peru and Vietnam

\begin{tabular}{llll}
\hline & Early Menarche & Late Menarche & Difference \\
\hline Peru & & & \\
\hline BMI at 8 & 17.07 & 16.50 & $0.57^{* *}$ \\
Height at 8 & 121.39 & 116.85 & $4.54^{* * *}$ \\
\hline \hline Vietnam & & & \\
\hline BMI at 8 & 14.75 & 13.91 & $0.84^{* * *}$ \\
Height at 8 & 122.19 & 117.53 & $4.66^{* * *}$ \\
\hline
\end{tabular}

Table A.2.2 Enrollment Across Rounds 1 and 2 for Girls in the Early Menarche Group, Peru

\begin{tabular}{|c|c|c|c|c|c|c|}
\hline & \multicolumn{3}{|c|}{ vs Late Menrache Girls } & \multicolumn{3}{|c|}{ vs Boys } \\
\hline & $(1)$ & $(2)$ & $(3)$ & (4) & $(5)$ & (6) \\
\hline \multirow[t]{2}{*}{ Early menarche } & $0.115^{* *}$ & -0.005 & 0.011 & $0.038^{*}$ & 0.026 & 0.034 \\
\hline & $(0.034)$ & $(0.027)$ & $(0.029)$ & $(0.021)$ & $(0.018)$ & $(0.020)$ \\
\hline \multirow[t]{2}{*}{ Round 2} & $0.106^{* * *}$ & 0.005 & 0.010 & 0.022 & -0.002 & -0.001 \\
\hline & $(0.024)$ & $(0.019)$ & $(0.019)$ & $(0.014)$ & $(0.017)$ & $(0.017)$ \\
\hline \multirow{2}{*}{ Early menarche X Round 2} & $-0.090^{* *}$ & -0.000 & -0.002 & -0.005 & -0.000 & -0.001 \\
\hline & $(0.030)$ & $(0.021)$ & $(0.021)$ & $(0.017)$ & $(0.017)$ & $(0.017)$ \\
\hline Observations & 663 & 619 & 619 & 980 & 964 & 964 \\
\hline$R^{2}$ & 0.0463 & 0.0682 & 0.134 & 0.00696 & 0.0439 & 0.0834 \\
\hline Control_average & 0.871 & 0.871 & 0.871 & 0.951 & 0.951 & 0.951 \\
\hline Cluster_FE & No & No & Yes & No & No & Yes \\
\hline Controls & No & Yes & Yes & No & Yes & Yes \\
\hline
\end{tabular}

Note: This table reports the results from difference-in-differences specification (see Equation 5.1). Controls include girl's natal home's household size, caste, sex of the household head, landholding in round 3, mom's schooling status, age of the head of the household, indicator of whether the girl speaks the majority language, number of younger siblings, number of older siblings, number of older brothers, number of older sisters, test scores at age eight, weight at age eight, and BMI at age eight. Sampling-site fixed effects are included. Robust standard errors clustered at the level of the sampling site are reported.

* Significant at $10 \% ; * *$ Significant at $5 \% ; * * *$ Significant at $1 \%$. 
Table A.2.3 Enrollment Across Rounds 1 and 2 for Girls in the Early Menarche Group, Vietnam

\begin{tabular}{|c|c|c|c|c|c|c|}
\hline & \multicolumn{3}{|c|}{ vs Late Menrache Girls } & \multicolumn{3}{|c|}{ vs Boys } \\
\hline & $(1)$ & $(2)$ & $(3)$ & $(4)$ & $(5)$ & (6) \\
\hline Early menarche & $\begin{array}{c}0.023 \\
(0.018)\end{array}$ & $\begin{array}{l}-0.017 \\
(0.012)\end{array}$ & $\begin{array}{l}-0.013 \\
(0.012)\end{array}$ & $\begin{array}{c}0.012 \\
(0.007)\end{array}$ & $\begin{array}{l}-0.008 \\
(0.005)\end{array}$ & $\begin{array}{l}-0.006 \\
(0.006)\end{array}$ \\
\hline Round 2 & $\begin{array}{c}-0.024 \\
(0.018)\end{array}$ & $\begin{array}{c}-0.050^{* *} \\
(0.015)\end{array}$ & $\begin{array}{c}-0.050^{* *} \\
(0.017)\end{array}$ & $\begin{array}{c}-0.020^{*} \\
(0.011)\end{array}$ & $\begin{array}{c}-0.030^{*} \\
(0.016)\end{array}$ & $\begin{array}{l}-0.027^{*} \\
(0.015)\end{array}$ \\
\hline Early menarche X Round 2 & $\begin{array}{c}0.024 \\
(0.018)\end{array}$ & $\begin{array}{l}0.045^{* *} \\
(0.018)\end{array}$ & $\begin{array}{c}0.048^{* *} \\
(0.019)\end{array}$ & $\begin{array}{c}0.020^{*} \\
(0.011)\end{array}$ & $\begin{array}{l}0.029^{* *} \\
(0.012)\end{array}$ & $\begin{array}{l}0.030^{\text {** }} \\
(0.012)\end{array}$ \\
\hline Observations & 1004 & 970 & 970 & 1210 & 1185 & 1185 \\
\hline$R^{2}$ & 0.0122 & 0.216 & 0.229 & 0.00890 & 0.0922 & 0.107 \\
\hline Control_average & 0.953 & 0.953 & 0.953 & 0.968 & 0.968 & 0.968 \\
\hline Cluster_FE & No & No & Yes & No & No & Yes \\
\hline Controls & No & Yes & Yes & No & Yes & Yes \\
\hline
\end{tabular}

Note: This table reports the results from difference-in-differences specification (see Equation 5.1). Controls include girl's natal home's household size, caste, sex of the household head, landholding in round 3, mom's schooling status, age of the head of the household, indicator of whether the girl speaks the majority language, number of younger siblings, number of older siblings, indicators for if the child has problem in reading and writing at age eight, weight at age eight, and BMI at age eight. Sampling-site fixed effects are included. Robust standard errors clustered at the level of the sampling site are reported.

* Significant at $10 \%$; ** Significant at $5 \%$; *** Significant at $1 \%$. 


\section{A.3 Robustness Checks}

\section{Figures}

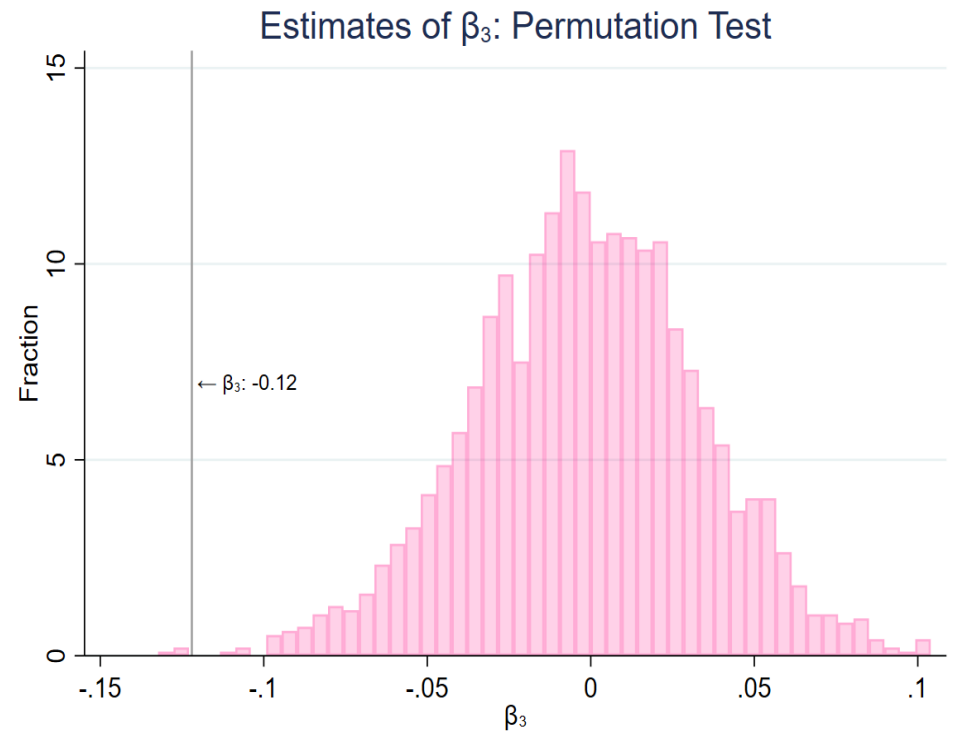

Figure A.3.1 Permutation Tests for Estimates of $\beta_{3}$. This figure shows the distribution of estimates of $\beta_{3}$ from a permutation test of for equation 5.1 when girls in the early menarche group are compared to girls in the late menarche group. For each child in the comparison sample, menarche status was randomly generated and these assignments were used to compute $\beta_{3} 2000$ times. This figure shows the distribution of the estimates of $\beta_{3}$ 


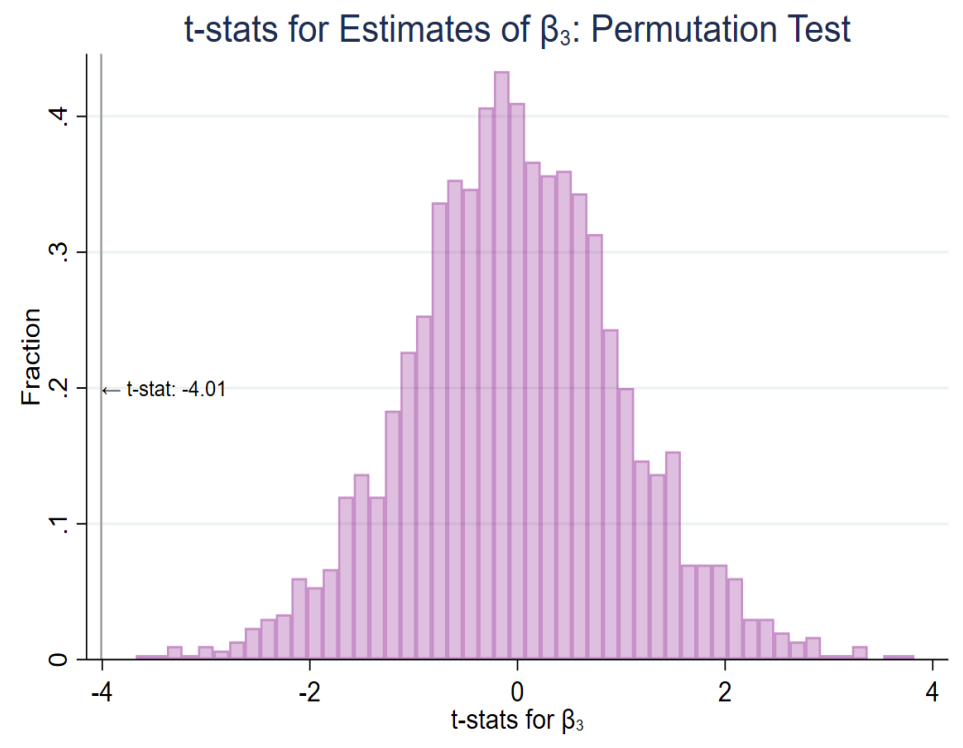

Figure A.3.2 Permutation Tests for Estimates of t-statistics for . This figure shows the distribution of estimates of $\beta_{3}$ from a permutation test of for equation 5.1 when girls in the early menarche group are compared to girls in the late menarche group. For each child in the comparison sample, menarche status was randomly generated and these assignments were used to compute $\beta_{3} 2000$ times. This figure shows the distribution of the estimates of the associated t-statistics

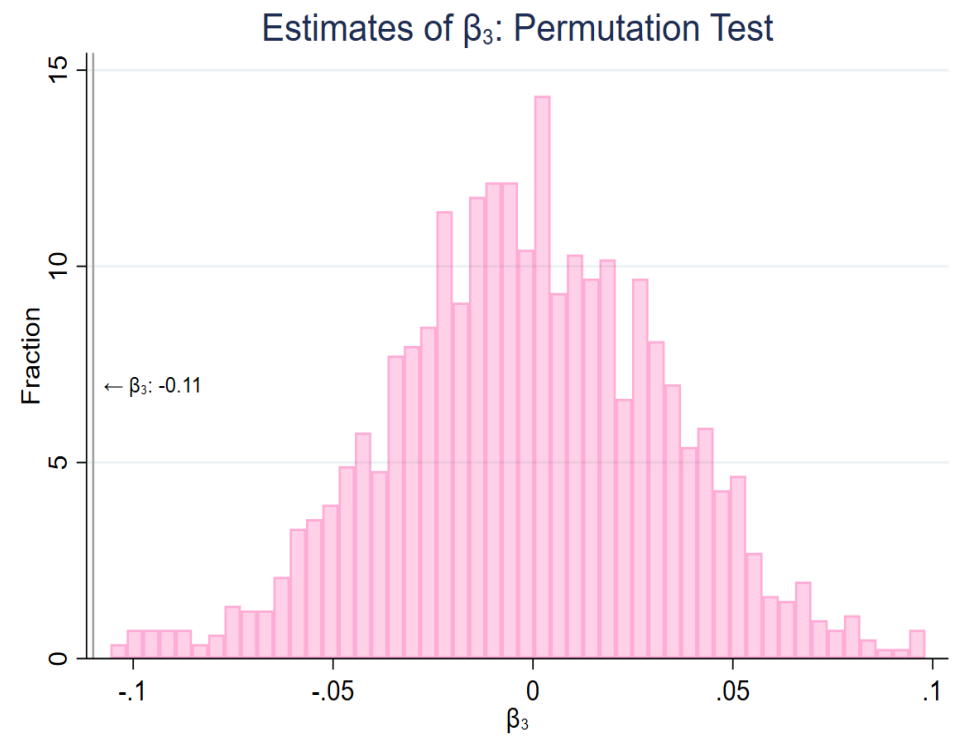

Figure A.3.3 Permutation Tests for Estimates of $\beta_{3}$. This figure shows the distribution of estimates of $\beta_{3}$ from a permutation test of for equation 5.1 when girls in the early menarche group are compared to boys. For each child in the comparison sample, menarche status was randomly generated and these assignments were used to compute $\beta_{3} 2000$ times. This figure shows the distribution of the estimates of $\beta_{3}$ 


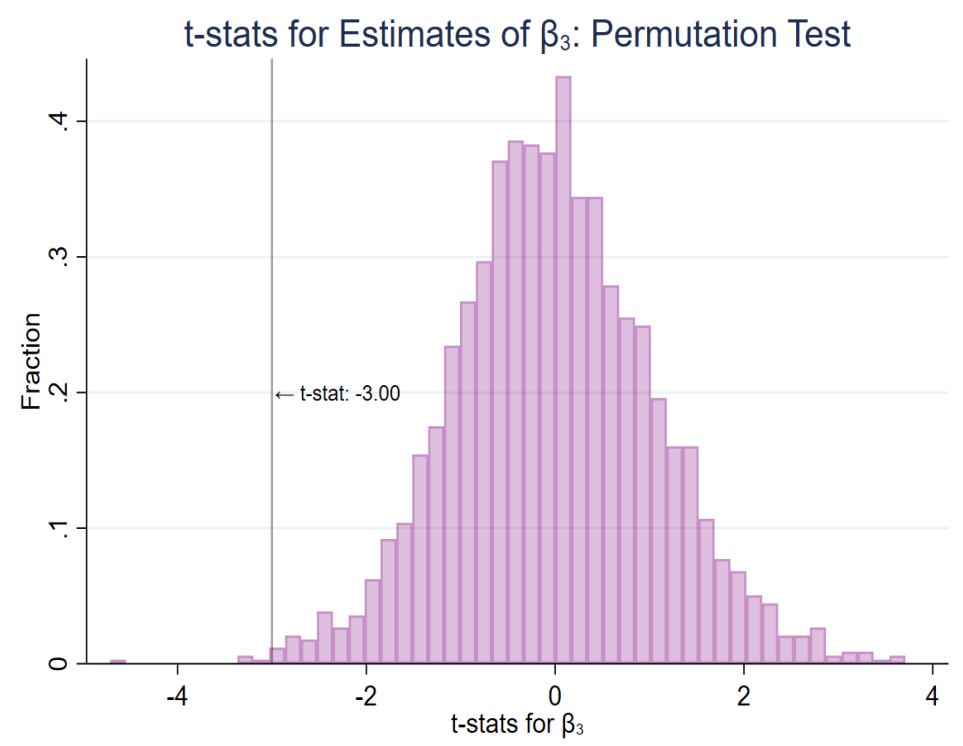

Figure A.3.4 Permutation Tests for Estimates of t-statistics. This figure shows the distribution of estimates of $\beta_{3}$ from a permutation test of for equation 5.1 when girls in the early menarche group are compared to boys. For each child in the comparison sample, menarche status was randomly generated and these assignments were used to compute $\beta_{3} 2000$ times. This figure shows the distribution of the estimates of the associated t-statistics 


\section{Tables}

Table A.3.1 Robustness Check- Including Health Shocks as a Control

\begin{tabular}{lcc}
\hline & $\begin{array}{c}(1) \\
\text { vs Late }\end{array}$ & $(2)$ \\
& Menarche Group & vs Boys \\
\hline Early menarche & 0.026 & -0.005 \\
& $(0.022)$ & $(0.014)$ \\
Round 2 & -0.034 & $-0.048^{* *}$ \\
& $(0.030)$ & $(0.018)$ \\
Early menarche X Round 2 & $-0.122^{* * *}$ & $-0.111^{* *}$ \\
& $(0.031)$ & $(0.037)$ \\
\hline Observations & 1013 & 1234 \\
$R^{2}$ & 0.162 & 0.129 \\
Control_average & 0.906 & 0.903 \\
Cluster_FE & Yes & Yes \\
Controls & Yes & Yes \\
\hline
\end{tabular}

Note: This table reports the results from difference-in-differences specification (see Equation 5.1) for comparisons that span the first and the second and the second and the third survey round. Controls include household size, caste, sex of the household head, wealth index,mom's literacy status, age of the head of the household, indicator of whether the child speaks the majority language, number of younger siblings, number of older siblings, number of older brothers, number of older sisters, test scores at age eight, weight at age eight, and BMI at age eight. Additionally, experience of health shocks in the past four years is included. Sampling-site fixed effects are included. Robust standard errors clustered at the level of the sampling site are reported.

* Significant at 10\%; ** Significant at 5\%; *** Significant at $1 \%$. 
Table A.3.2 Robustness Check- Individual Fixed Effects

\begin{tabular}{lcc}
\hline & $\begin{array}{c}(1) \\
\text { vs Late }\end{array}$ & $(2)$ \\
& Menarche Group & vs Boys \\
\hline Round 2 & -0.009 & -0.030 \\
& $(0.037)$ & $(0.036)$ \\
Early menarche X Round 2 & $-0.130^{* *}$ & $-0.109^{* *}$ \\
& $(0.045)$ & $(0.052)$ \\
\hline Observations & 1013 & 1234 \\
$R^{2}$ & 0.604 & 0.599 \\
Control_average & 0.906 & 0.903 \\
Individual_FE & Yes & Yes \\
Controls & Yes & Yes \\
\hline
\end{tabular}

Note: This table reports the results from difference-in-differences specification (see Equation 5.1). Controls include number of younger siblings, number of older siblings, number of older brothers and number of sisters. Individual fixed effects are also included. Robust standard errors clustered at the level of the sampling site are reported.

* Significant at $10 \% ; * *$ Significant at $5 \% ; * * *$ Significant at $1 \%$. 


\section{A.4 Heterogeneity in Impact on Enrollment: Additional Results}

After menarche, the consequences of failing to ensure the girl's safety are more severe. As a result, additional restrictions are imposed on the extent of her social interactions and mobility. These restrictions are definitely binding if the girl has to travel a long distance to attend school. The decrease in enrollment rate due to menarche is muted if she resides in a community that has a secondary school (Table A.4.1). Perhaps due to a small sample size, the triple-difference estimate is not statistically significant.

Along with the availability of schools in the neighborhood, availability of sanitation facilities at these schools could also characterize the local safety environment when a girl goes to school after her menarche (Adukia, 2018). As discussed in Section 2, qualitative reports describe that girls miss school during their menses because of a lack of sanitation facilities at their schools. To explore if menarche makes the concerns regarding lack of sanitation facilities more salient, data from the District Information System for Education ${ }^{b}$ for Andhra Pradesh for 2006 is used to classify the Young Lives study districts into two groups: one group where the availability of toilets for girls is above the state median ( $65 \%$ of schools in a district), and one where the availability of toilets for girls is below the state median. ${ }^{c}$ As a result of menarche, the decrease in enrollment is larger in the latter group (Table A.4.1). As before, the difference between these estimates is not significant.

Next, safety concerns are likely to be more serious in the communities with higher level of crime. To quantify the local crime environment, a 'crime-index' is computed using the incidence of different types of crimes reported in the community focus-group discussion in the second survey round. The impact of menarche on enrollment is not different across the sub-samples defined by high or low crime-index (Table A.4.2). Decrease in enrollment due to menarche is not mitigated by the presence of a police station in the community (Table A.4.2). However, crime-index and presence of a police station may not represent the children's (and their parents') perceptions of safety of their neighborhood. This is especially true since the presence of police stations is ineffective in deterring actual incidents of crime against women (Basu Roy \& Dastidar, 2018).

\section{References}

Adukia, A. (2018). Sanitation and education. American Economic Journal: Applied Economics, $9(2), 23-59$.

Basu Roy, S., \& Ghosh Dastidar, S. (2018). Why do men rape? Understanding the determinants of rapes in India. Third World Quarterly, 1-23.

\footnotetext{
${ }^{\mathrm{b}}$ District Information System for Education is a database of all the schools in India. It is updated annually.

${ }^{\mathrm{c}}$ To protect the privacy of the children followed in the Young Lives study, any information on the location of their residence is not shared with external researchers. The lowest level at which their location can be identified is a district.
} 


\section{Tables}

Table A.4.1 Table D1 Impact of Early Menarche of Enrollment, by School Infrastructure

\begin{tabular}{lcc}
\hline & $\begin{array}{c}(1) \\
\text { Secondary School } \\
\text { Presence }\end{array}$ & $\begin{array}{c}\text { Female Toilets } \\
\text { Availability }\end{array}$ \\
\hline Early menarche X Round 2 & $-0.146^{* *}$ & $-0.113^{* *}$ \\
& $(0.059)$ & $(0.051)$ \\
Early menarche X Round 2 X Secondary School Present & 0.035 & \\
Early menarche X Round 2 X Lower Toilet Availability & $(0.071)$ & \\
& & -0.015 \\
\hline Observations & & $(0.064)$ \\
$R^{2}$ & 1013 & 1013 \\
Control_average & 0.170 & 0.162 \\
Cluster_FE & 0.906 & 0.906 \\
Controls & Yes & Yes \\
\hline
\end{tabular}

Note: This table reports the results from a triple-difference specification (see Equation 5.2) for comparisons that span the first and the second survey rounds. Column (1) reports results when the difference-in-differences specification is interacted with the presence of a secondary school in the community and Column (2) reports results when the difference-in-differences specification is interacted with if the girl resides in a district where the availability of toilets for girls in schools is greater than the median availability in the state. Controls include household size, caste, sex of the household head, wealth index,mom's literacy status, age of the head of the household, indicator of whether the child speaks the majority language, number of younger siblings, number of older siblings, number of older brothers, number of older sisters, test scores at age eight, weight at age eight, and BMI at age eight. Sampling-site fixed effects are included. Robust standard errors clustered at the level of the sampling site are reported.

* Significant at $10 \%$; ** Significant at $5 \%$; ** Significant at $1 \%$. 
Table A.4.2 Impact of Early Menarche of Enrollment, by Local Crime Environment

\begin{tabular}{lcc}
\hline & $\begin{array}{c}(1) \\
\text { Community Crime } \\
\text { Index }\end{array}$ & $\begin{array}{c}(2) \\
\text { Police Station Present } \\
\text { of Safety }\end{array}$ \\
\hline Early menarche X Round 2 & $-0.118^{* *}$ & $-0.116^{* *}$ \\
& $(0.044)$ & $(0.044)$ \\
Early menarche X Round 2 X Low crime community & -0.008 & \\
& $(0.076)$ & -0.009 \\
Early menarche X Round 2 X Police Station Present & & $(0.075)$ \\
\hline Observations & & 991 \\
$R^{2}$ & 1013 & 0.164 \\
Control_average & 0.165 & 0.906 \\
Cluster_FE & 0.906 & Yes \\
Controls & Yes & Yes \\
\hline
\end{tabular}

Note: This table reports the results from difference-in-differences specification (see Equation 5.1) for comparisons that span the first and the second survey rounds. Controls include household size, caste, sex of the household head, wealth index,mom's literacy status, age of the head of the household, indicator of whether the child speaks the majority language, number of younger siblings, number of older siblings, number of older brothers, number of older sisters, test scores at age eight, weight at age eight, and BMI at age eight. Sampling-site fixed effects are included. Robust standard errors clustered at the level of the sampling site are reported.

* Significant at $10 \%$; * Significant at 5\%; *** Significant at $1 \%$. 


\section{A.5 Early Menarche as an Instrument for Early Marriage}

This section will explore the validity of early menarche as an instrument for early marriage. Following Conley, Hansen \& Rossi (2012), the plausible violation of the exclusion restriction is understood through the lens of the following population model:

$$
Y=X \beta+Z \kappa+\epsilon
$$

Violation of the exclusion restriction would imply that $\kappa$ is not zero. Under certain assumptions of the point estimate of $\kappa$ or on the distribution it is drawn from, one can estimate bounds around the two-stage least squares estimate. Let's assume that $\kappa$ is drawn from the support $G$, and the true value is $\kappa_{0} \in G$. Subtracting $Z \kappa_{0}$ from both sides of equation A.5.1:

$$
Y-Z \kappa_{0}=X \beta+\epsilon
$$

For all points in the support $G$, one can estimate the $95 \%$ confidence interval around $\beta^{I V}$ using two methods. The union of confidence intervals method assumes that only the support of $\kappa$ is known, and the union of confidence intervals corresponding around $\beta^{I V}$ for different values of $\kappa$ in $G$ will contain the population parameter. A primary drawback of this methodology is that the confidence intervals are often too wide. A second methodology discussed by Conley, Hansen \& Rossi (2012) assumes that $\kappa$ is a random draw from a known distribution and the knowledge of this distribution is used to compute the $95 \%$ bounds around the population parameter.

The paper uses these methodologies to discuss the validity of early menarche as an instrument for early marriage. First, $\kappa$ is estimated using the Young Lives study. Next, nationally represntative IHDS data is used to estimate the effect of early marriage on completed schooling using an instrumental variable strategy and explore the stability of this estimate for the estimate of $\kappa$ derived in the first step. Two specifications are considered in the first step: one with sampling site fixed effects (the preferred specification in the paper) and one with district fixed effects (the specification than can be estimated with the IHDS data).

Estimates of $\kappa$ from the Young Lives study

As discussed in Section 6, reaching menarche before twelve leads to a $13.4 \%$ decline in school enrollment rate, and this result is supported by a variety of robustness checks. Table A.5.1 describes the relationship between early menarche and completed education. ${ }^{\mathrm{d}}$ The difference in the completed years of education for girls in the early and the late menarche groups is 1.2 years, that is, girls in the early menarche group get 1.2 years less education, on average than other girls in their cohort. This estimate reduces to 0.79 years when their marital status is included. We can take the estimate

\footnotetext{
${ }^{\mathrm{d}}$ For the girls who are still enrolled at twenty-two, the completed education is taken to be their current completed education.
} 
of the relationship between early menarche and years of schooling to recover the bounds around the two-stage least squares estimates. These specifications are also replicated with district fixed effects instead of sampling site fixed effects. The results are qualitatively similar, albeit more precise. Finally, the last column presents the results of the effect of being unmarried by eighteen on completed schooling while using early menarche to isolate the variation in the timing of menarche. The identifying equation are:

$$
\begin{aligned}
\text { Second Stage : YearsSchooling } & =\beta \text { Unmarriedby } 18_{i d}+\gamma X_{i d}+\eta_{d}+\epsilon_{i d} \\
\text { First Stage : Unmarriedby } 18_{i d} & =\rho \text { EarlyMenarche } e_{i d}+\gamma X_{i d}+\eta_{d}+\mu_{i d}
\end{aligned}
$$

where YearsSchooling $i d$ is the completed years of schooling for woman $i$ in district $d$, Unmarriedby $18_{i d}$ is an indicator equal to one when the woman had not married by eighteen and EarlyMenarche id $_{\text {is }}$ an indicator equal to one if the woman started menstruating before twelve. $X_{i d}$ denotes a vector of additional controls and $\eta_{d}$ denotes district fixed effects. ${ }^{\mathrm{e}}$ The two-stage least squared estimate is 9.2 years. However, F-statistic from the first stage is only 7.3, and the problem of a weak instrument renders these results not suitable for estimating bounds around the two-stage least squares estimates (Conley, Hansen \& Rossi, 2012). ${ }^{\mathrm{f}}$ Therefore, the following discussion explores the stability of these estimates using a larger nationally representative dataset.

\section{Two-stage Least Squares Estimation Using the IHDS Data}

The second round of the IHDS was conducted in 2011-12. The interviews with ever-married women aged 15-49 collected recall data on age at menarche, years of schooling and age at first marriage. As is common for the literature that uses the timing of menarche as an instrument for the timing of marriage, the sample is restricted to women who were still in school at age nine (Field \& Ambrus, 2008). In addition, the sample is restricted to those who were married after menarche. ${ }^{\mathrm{g}}$ The distribution of the difference between age at dropout and age at menarche is bimodal, where one of the two peaks is at zero: a substantial mass of girls drop out of school right after menarche (Figure A.5.1). The distribution of the the difference between at age at dropout and age at menarche shows that most girls marry about five years after dropping out of school.

For estimating results that are comparable to the ones described in Table A.5.1, controls were chosen to be as similar to the set of controls included in the preferred specification estimated using data from the Young Lives study. The final set of controls include current land ownership, current log per capita consumption, age, age-squared, location of residence (urban or rural) and number of members in the household. In addition, variables that capture some information about the woman's natal home are included: indicator for if the natal home is economically better off than the marital home, father's education, mother's education, number of brothers and number of sisters. The IHDS data does not contain the information of the geographical location of the woman's natal home. To somewhat capture her childhood experiences that may be correlated to her schooling, district fixed

\footnotetext{
${ }^{\mathrm{e}}$ Since the evidence from the IHDS data uses district fixed effects, district fixed effects are included.

${ }^{\mathrm{f}}$ The $95 \%$ confidence interval using the union of confidence intervals method is [-4.6, 15.8] and using the local to zero method when it is assumed that $\kappa$ is drawn from a uniform distribution on the support $(-0.87,1)$ is $[-0.4,14.6]$.

${ }^{g}$ These restrictions are not binding in the case of estimates from the Young Lives study described above.
} 
effects are included; Bloch, Rao, \& Desai (2002) estimate that the average distance from between martial and natal homes is 21 miles, and therefore her natal home is likely to fall within the district of current residence. Robust standard errors clustered at the level of a district are reported.

The two-stage least squared estimates show that being unmarried by eighteen increases schooling by 4.6 years (Table A.5.1). The $95 \%$ confidence interval estimated using the union of confidence intervals method is $[-10.2,6.1]$ when $\kappa$ lies in the support $[-0.87,0] .{ }^{\mathrm{h}}$ To implement the local-to-zero method, it is assumed that $\kappa$ is drawn from a uniform distribution on the support $(\delta, 0)$. The $95 \%$ confidence interval in this case when $\kappa$ is -0.87 is $[-7.6,4.6]$. Thus, the two-stage least squares estimates are not robust to departures from the exclusion restrictions. Figure A.5.2 and Figure A.5.3 describe the $95 \%$ confidence intervals for different levels of departure from the exclusion restriction.

\section{References}

Conley, T. G., Hansen, C. B., \& Rossi, P. E. (2012). Plausibly exogenous. Review of Economics and Statistics, 94(1), 260-272.

Bloch, F., Rao, V., \& Desai, S. (2004). Wedding celebrations as conspicuous consumption signaling social status in rural India. Journal of Human Resources, 39(3), 675-695.

Field, Erica, and Attila Ambrus. 2008. Early marriage, age of menarche, and female schooling attainment in Bangladesh. Journal of Political Economy,116(5): 881-930.

\footnotetext{
${ }^{\mathrm{h}}$ The estimated value of $\kappa$ from the Young Lives Study is -0.86 . Therefore, it is taken to be the upper bound of the violation of the exclusion restriction.
} 


\section{Figures}

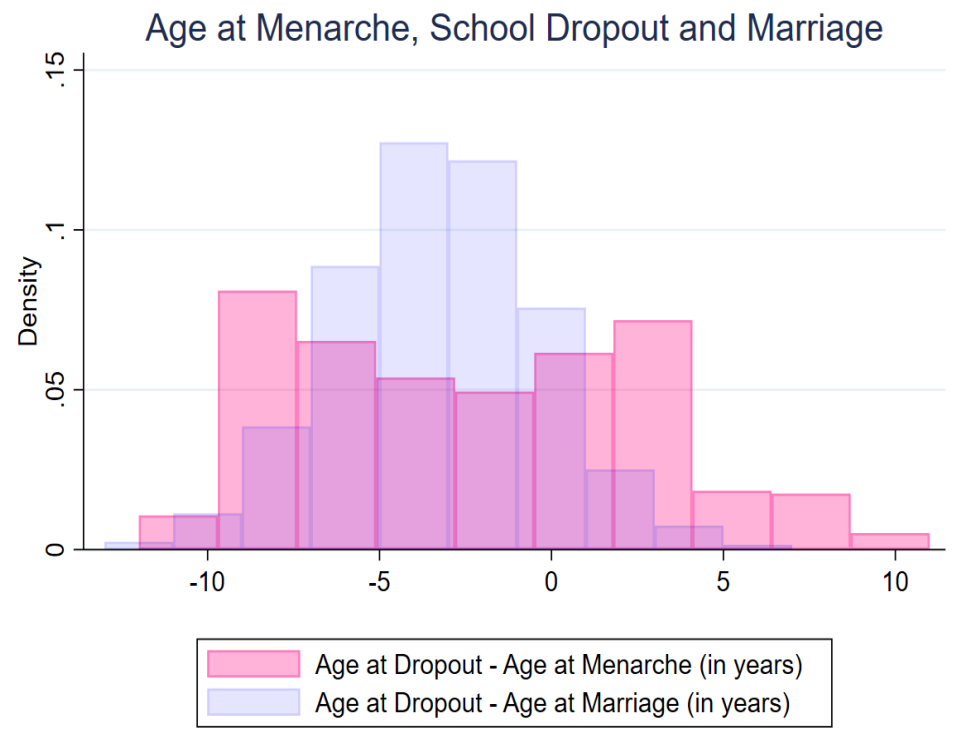

Figure A.5.1 Age at Marriage, School Dropout and Marriage. Data are taken from the IHDS. The histogram in the lighter (pink) shade represents the difference between the age at which girls drop out of school and the age at which they reached menarche (in years) and the histogram in the darker (purple) shade represents the difference between the age at which girls drop out of school and the age at which they get married (in years).

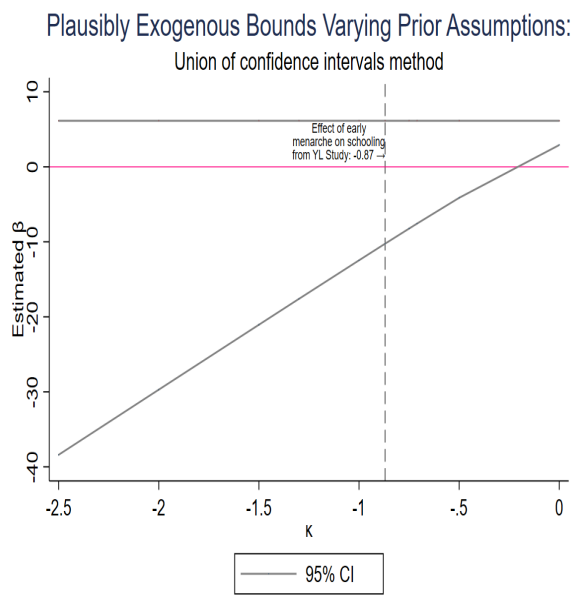

Figure A.5.2 95\% CI Around IV Estimates, UCI Method. Data are taken from the IHDS. Grey lines represent the $95 \%$ CI derived using the UCI method.

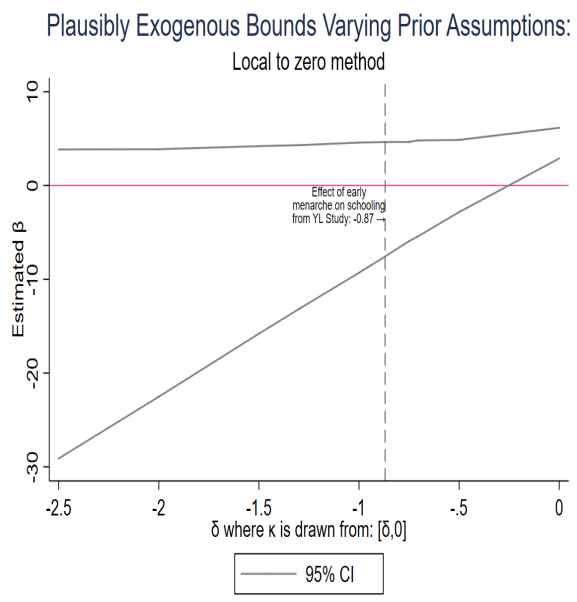

Figure A.5.3 95\% CI Around IV Estimates, LTZ Method. Data are taken from the IHDS. Grey lines represent the $95 \%$ CI derived using the LTZ method. 


\section{Tables}

Table A.5.1 Menarche and Years of Schooling, Evidence from the YL Study

\begin{tabular}{lcccc|cc}
\hline & $(1)$ & $(2)$ & $(3)$ & $(4)$ & $($ OLS $)$ & $(2 S L S)$ \\
\hline Early menarche & $-1.165^{* *}$ & $-0.791^{*}$ & $-1.263^{* *}$ & $-0.867^{* *}$ & & \\
& $(0.509)$ & $(0.435)$ & $(0.389)$ & $(0.243)$ & & \\
Unmarried by 18 & & $2.798^{* * *}$ & & $2.881^{* * *}$ & $2.978^{* * *}$ & $9.196^{* * *}$ \\
& & $(0.410)$ & & $(0.333)$ & $(0.350)$ & $(1.045)$ \\
\hline Observations & 479 & 479 & 479 & 479 & 479 & 479 \\
$R^{2}$ & 0.270 & 0.366 & 0.235 & 0.340 & 0.332 & 0.163 \\
Control_average & 13.34 & 13.34 & 13.34 & 13.34 & 13.34 & 13.34 \\
Cluster_FE & Yes & Yes & Yes & Yes & Yes & Yes \\
District_FE & No & No & Yes & Yes & Yes & Yes \\
Controls & Yes & Yes & Yes & Yes & Yes & Yes \\
Fstat & & & & & & 7.330 \\
\hline
\end{tabular}

Note: Columns (1)-(4) report results from single-difference specification (see Equation 5.3). Controls include household size, caste, sex of the household head, wealth index,mom's literacy status, age of the head of the household, indicator of whether the child speaks the majority language, number of younger siblings, number of older siblings, number of older brothers, number of older sisters, test scores at age eight, weight at age eight, and BMI at age eight. In columns (1)-(2), sampling site fixed effects are included and standard errors are clustered at the sampling site level. In columns (3)-(4), district fixed effects are included and standard errors are clustered at the district level. The last two columns present the results on the effect of being unmarried until eighteen on completed schooling using OLS and 2SLS specifications. Estimation is restricted to those who droppped out of school after ten.

* Significant at $10 \% ; * *$ Significant at $5 \% ; * * *$ Significant at $1 \%$. 
Table A.5.2 Menarche and Years of Schooling, Evidence from the IHDS Data

\begin{tabular}{lcc|cc}
\hline & $(1)$ & $(2)$ & $(3)$ & $(4)$ \\
& $(1)$ & $(2)$ & OLS & 2SLS \\
\hline Early Menarche & $-0.334^{* * *}$ & $-0.219^{* *}$ & & \\
& $(0.071)$ & $(0.066)$ & & \\
Single by 19 & & $\begin{array}{c}1.593^{* * *} \\
(0.049)\end{array}$ & $1.600^{* * *}$ & $4.604^{* * *}$ \\
& & $0.049)$ & $(0.975)$ \\
\hline Observations & 21591 & 21591 & 21591 & 21591 \\
$R^{2}$ & 0.391 & 0.440 & 0.440 & 0.265 \\
Control_average & 3.907 & 3.907 & 3.907 & 3.907 \\
District_FE & Yes & Yes & Yes & Yes \\
Controls & Yes & Yes & Yes & Yes \\
Fstat & & & & 42.03 \\
\hline
\end{tabular}

Note: Columns (1)-(2) report results from single-difference specification (see Equation 5.3).

Controls include household size, caste, age, age-squared, log per capita consumption, indicator for land ownership, location (rural or urban), indicator if the natal home if economically better-off, mother's education, father's education, mother's education, number of brothers and number of sisters. District fixed effects are included and standard errors are clustered at the district level. The last two columns present the results on the effect of being unmarried until eighteen on completed schooling using OLS and 2SLS specifications. Estimation is restricted to those who droppped out of school after ten and married after menarche.

* Significant at 10\%; ** Significant at 5\%; *** Significant at $1 \%$. 